\title{
XXV.
}

\section{Beiträge zur pathologischen Anatomie der Rückenmarkscompression.}

(Aus dem Kgl. Pathologischen Institut der Universität Breslau.)

Von Drd. med. Bruno Heymann,

z. Z. Assistenzarzt an der inneren Abtheilung des städtischen Krankenhospitals zu Allerheiligen in Breslau.

(Hierzu Taf. XI.)

Trotz des fast überreichen casuistischen Materials ${ }^{1}$ ) von Fällen sog. Compressionsmyelitis sind die Anschaungen über die tieferen anatomischen und ätiologischen Momente noch immer nicht ganz geklärt. Diese Thatsache muss den historischen Betrachter um so mehr überraschen, als Anfangs, beim ersten Bekanntwerden dieses Krankheitsbildes, besonders die Genese der Compressionsveränderungen sehr durchsichtig und einer überaus einfachen Erklärung zugänglich zu sein schien. Die unzweideutigen Bilder von schwerer Zermalmung des Rückenmarks durch cariöse, zusammengesunkene Wirbelfragmente, die manchmal geradezu bandartige, manchmal nicht mehr als federkieldicke Zusammenpressung des erweichten Centralorgans durch einen andrängenden Tumor, durch die verdickte Dura mater spinalis verführten begreiflicherweise die ersten Beobachter dazu, die Erweichung lediglich auf die grobmechanische Wirkung der Zusammendrückung zurückzuführen. So sagt 0llivier in seinem berühmten Werke "Traité de la moëlle épinière et de ses maladies" "2): "Es erzeugt ein örtlicher, lange dauernder und stufenweise auftretender Druck eine Verdickung in den Häuten des Rücken-

1) Vergl, u. A.: Grawitz, Klinische und anatomische Beiträge zur Kenntniss der Drucklähmungen des Rückenmarks. Charité-Annalen. XX. S. 169.1895.

2) Ollivier, Traité de la moëlle épinière et de ses maladies. Paris 1827. Deutsch übersetzt und mit Zusätzen vermehrt von Dr. J. Radius. Leipzig 1824. S. 202. 
ปे
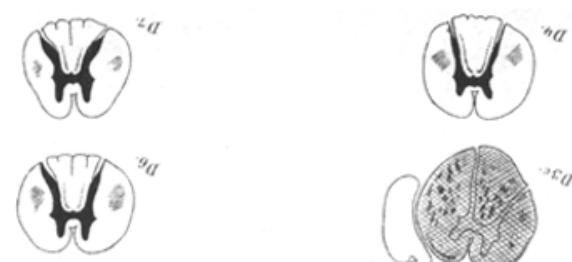

(H)

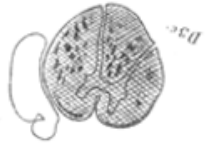

(4.)

(4)

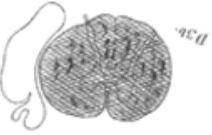

(4)

(4)

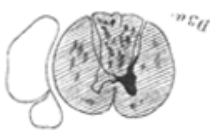

(1)

(4)
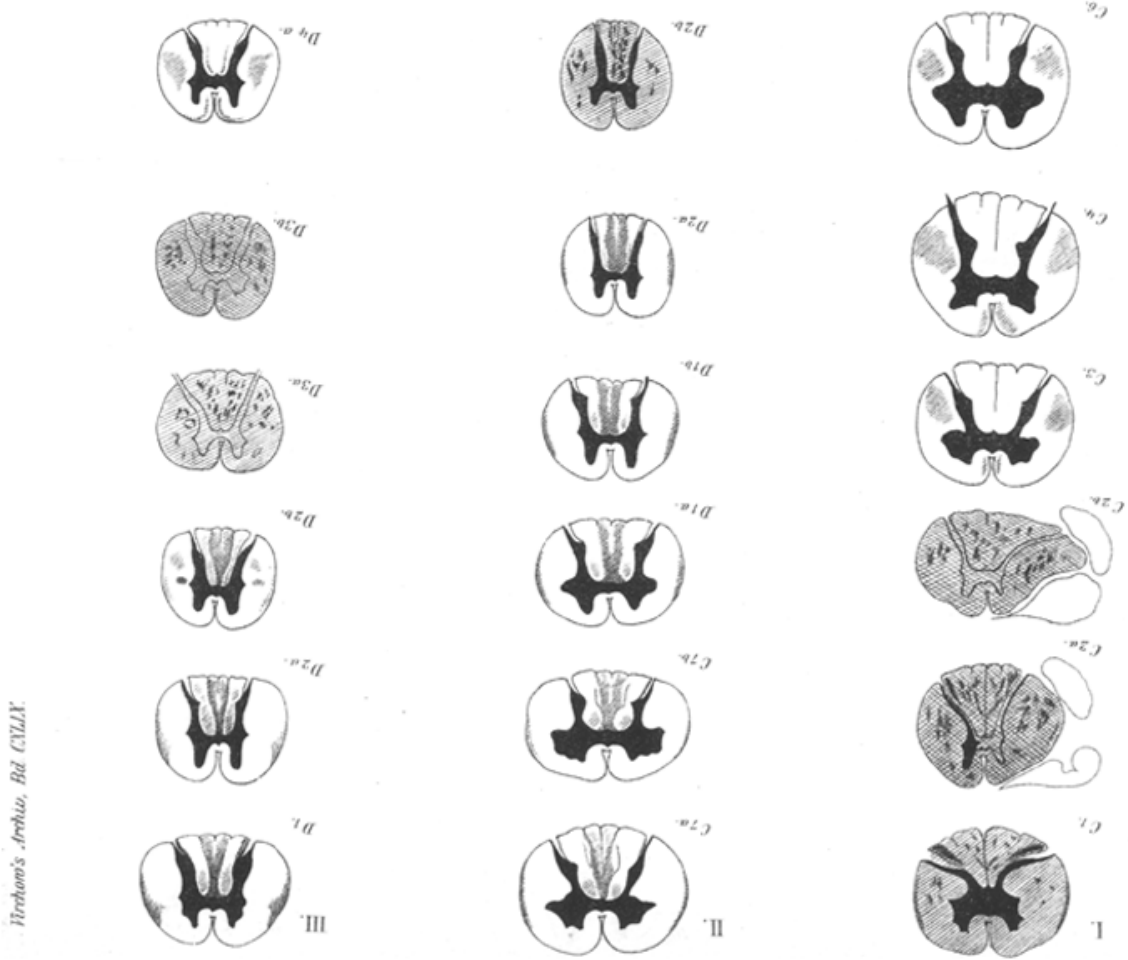
marks und eine merkliche Erweichung in seiner Substanz, ohne anderweitige Desorganisation", und neben anderen Autoren bestätigte und erweiterte besonders Louis ${ }^{1}$ ) seine Angaben.

Allein bald musste diese einfache Anschauung weiteren, widersprechenden Beobachtungen weichen. Es wurden Fälle bekannt, in denen die Compression als solche nur sehr gering gewesen sein konnte, wo sich nur eine schwache oder gar keine Deformität am Centralorgan vorfand, ja es gesellten sich merkwürdige Fälle hinzu, in denen dasselbe nicht nur nicht comprimirt, sondern sogar in seinem Volumen entschieden vergrössert war. Kam durch diese Erfahrungen die alte Theorie schon mehr und mehr in Misscredit, so wurde sie schliesslich ganz und gar durch die Entdeckungen gestürzt, die im Gefolge der grossen Arbeiten Türck's ${ }^{2}$ ), Charcot's ${ }^{3}$ ) und Bouchard's ${ }^{4}$ ) über die secundäre Degeneration gemacht wurden. Man sah in dem erweichten Gewebe Vermehrung der Gefässe, sowie des $Z$ wischengewebes, man fand in ihm zahlreiche Körnchenzellen vor, die man für Produkte der Entzündung ansah, und begründete darauf eine neue Theorie, nach welcher die Rückenmarksveränderungen nichts anderes als reactive, entzündliche seien, man kam zum Begriff der Rückenmarksentzündung durch Druck, der Compressionsmyelitis im eigentlichen Sinne des Wortes. Diese neue Auffassung fand in kurzer Zeit allgemeinen Anklang. Denn nicht nur, dass sie in der That alle die auffälligen Beobachtungen zu erklären schien, wurde sie auch von Männern erster Autorität mit Freude begrüsst und durch immer neue Beweise gestützt. Es war vor Allem die Schule Charcot's [besonders ihr Anhänger Michaud ${ }^{5}$ )], die den grössten Werth

1) Louis, Mémoire sur l'état de la moëlle dans la carie vertébrale. Paris 1826.

2) Türck, Sitzungsberichte der mathem.-naturwissenschaftl. Klasse der k. k. Akademie der Wissenschaften. 1851. S. 291. 1853. S. 111.

3) Charcot, Leçons sur les maladies du système nerveux, faites a la Salpetrière, 2. fasc. de la compression lente de la moêlle épinière, und Gaz. méd. 1874. No. 49.

4) Bouchard, Dictionn. encyclopédique mal. II. Sér. T. VIII. Arch. général. de méd. 1866. Vol. I, II.

5) Michaud, Sur la meningite et la myélite dans le mal vértebral. Thèse. Paris 1871 . 
auf die entzündlichen Vorgänge legte und die Compressionsdegenerationen zu den interstitiellen Myelitiden rechnete, indem sie so eine Brücke zwischen den acuten und chronischen Formen schlug und, um mit $\mathrm{Erb}^{1}$ ) zu reden, „ein verbindendes Band zwischen sehr weit auseinanderliegenden Krankheiten" schuf. Auch in England und Deutschland fand diese Lehre eifrige Verfechter. So fasst Leyden ${ }^{2}$ ) in seinem klassischen Werke über Rückenmarkskrankheiten die Compressionsmyelitis - nicht nur die durch tuberculöse Wirbelcaries, sondern auch die durch Tumoren und sonstige rein mechanische Ursachen hervorgerufene Erkrankung - als reine Entzündung auf, indem er als Agens derselben den Reiz betrachtet, den ,schon ein geringer Druck, ja ein Contact mit dem hervorbrechenden Carcinom" abgebe und "genügend sei, um durch die intacten Häute hindurch in der Substanz des Rückenmarks Entzündung und Erweichung hervorzurufen", und stellte in Anbetracht des Umstandes, dass er histologisch scheinbar ganz identische Verhältnisse vorfand, die acute Myelitis und die oft nachweislich monatelang andauernde Compressionsmyelitis auf ein und dieselbe Stufe.

Diese Anschaungen, z. B. auch von Frommann ${ }^{3}$ ) vertreten, genossen lange Zeit allgemeine Anerkennung und ein beinahe dogmatisches Vollgewicht, und erst in neuerer Zeit begannen sich $Z$ weifel an sie zu regen. In der Einleitung zu Kahler's ${ }^{4}$ ) berühmt gewordener Arbeit über experimentelle Rückenmarkscompression finden sich folgende Sätze, die ich wörtlich citiren möchte, weil sie kurz und treffend das Facit aus den früheren Arbeiten ziehen: „Die Ursache der bei Compressionsmyelitis beschriebenen Veränderungen der Rückenmarkssubstanz, mögen diese nun schon mehr interstitieller oder parenchymatöser Natur sein, sucht man zur Zeit allgemein in dem Entzündungsreize, der durch die Compression entsteht und supponirt für solche Fälle, wo die Krankheitserscheinungen sich,

1) Erb, Ziemssen's Handbuch. Bd. 11, 2. S. 319.

2) Leyden, Klinik der Rückenmarkskrankheiten. Bd. I. S. 297. 1874.

3) Frommann, Ein Fall von Wirbelcaries mit Degeneration des Rückenmarks. Dieses Archiv. Bd.54.

4) Kabler, Veränderungen am Rückenmark in Folge geringgradiger Compression. Zeitschr. fär Heilkunde. 1882. 
ohne dass eine wesentliche Zunahme der Compression beschuldigt werden könnte, auffallend rasch entwickelt haben, eine hinzugetretene, ihrer Natur nach unbekannte Entzündungsursache.

So steht es mit unserer Kenntniss der Erscheinungen und des Wesens der durch langsame Compression bedingten Rückenmarkserkrankung, und es bedarf wohl keiner weiteren Ausführungen, um das Unbefriedigende dieses Standes unseres Wissens zu beweisen. Was das Wesen des Prozesses betrifft, sind wir genöthigt, uns mit der Hypothese abzufiuden, dass die Compression als Entzündungsreiz wirke, oder müssen gar das zufällige Hinzutreten einer Noxe supponiren, die aus dem locus minoris resistentiae zu Entzündung führt, und die pathologische Histologie der Compressionsmyelitis betreffend, sind wir nicht viel besser daran, denn es fehlt uns vorläufig jede Kenntniss der primär durch die Compression gesetzten Veränderungen, und damit jede Einsicht in das gegenseitige Verhältniss der parenchymatösen und interstitiellen Gewebserkrankung."

Mangels geeigneten klinischen Materials bediente sich Kahler folgender Versuchsanordnung:

Er injicirte jungen Hunden extradural in den Wirbelkanal nüssiges Wachs in ziemlich beträchtlicher Menge, so dass die erstarrten Massen in einer Dicke von 2 bis $5 \mathrm{~mm}$ die Dura bedeckten und die anliegenden Theile des Rückenmarks comprimirten, und tödtete die Thiere verschieden lange Zeit nach der Injection. Auf Grund eingehender makro- und mikroskopischer Studien besonders der Compressionsstelle gelangte nun Kahler zu folgenden Resultaten: "Die Compression, die das Rückenmark von Hunden durch in den Wirbelkanal injicirtes Wachs erleidet, führt zu primären Veränderungen an den Nervenfasern, die unter bedeutender Anschwellung ihrer Theile, namentlich des Axencylinders zerfallen und schliesslich verschwinden. Erst secundär kommt es zu einer Betheiligung des interstitiellen Gewebes und der Gefässe an dem Prozesse." Entzündungserscheinungen hat Kahler primär nie beobachtet; den Gedanken, dass die Veränderungen vielleicht durch die Wärme des Injectionsmaterials hervorgerufen sein könnten, weist er mit Erfolg zurück - woher also stammten dieselben? Kahler recurrirte auf die alte mechanische Theorie und verwerthete sie zusammen 
mit neueren Erfahrungen zum Aufbau einer neuen. Eingedenk der Thatsache, dass er die Veränderungen der Nervenfasern nur an den Stellen vorfand, wo sich grössere Mengen Wachs angesammelt hatten, also eine "halbwegs stärkere" Compression eingetreten war, hielt er zunächst daran fest, dass die Compression als solche einen schädigenden Einfluss auf die Nervenfasern ausüben müsse. Diesen legte er dahin aus, dass ihr normaler $\mathrm{Zu}$ sammenhang mit dem trophischen Centrum gestört werde und sie daher weiteren Schädlichkeiten eher verfielen als im normalen Zustande. Diese zweite Noxe sucht Kahler in den Gewebssäften. Durch die Arbeiten Rumpf's $\left.{ }^{1}\right)^{2}$ ) war festgestellt, dass Lymphe sowohl auf die peripherischen Nervenfasern wie auf die Centralorgane einen starken, zerstörenden Einfluss ausübe und Schwellung und Quellung der Fasern und auch sonst ganz gleiche Veränderungen hervorrufe, wie Kahler an den Compressionsstellen sah. War also schon an sich ein Einfluss der Lymphe auf die in ihrem physiologischen Verhalten im Sinne einer grösseren Verletzbarkeit veränderten Nervenfasern denkbar, so kam als ein weiteres, stützendes Moment noch die Behinderung des Lymphabflusses und dadurch die Staung der Gewebssäfte hinzu, die nach seiner Meinung der Druck auf die grossen Gefässe hervorrufen musste. Nach Kahler also handelte es sich wiederum um mechanische Ursachen, um eine Einwirkung gestauter Gewebssäfte auf Nervenfasern, deren Ernährung in Folge von Compression eine unzureichende geworden war.

Diese neue Theorie fand, obschon ihr Begründer selbst äusserst vorsichtig im Ziehen weiterer Schlüsse, besonders auf die menschliche Pathologie, war, in Kurzem einen bedeutenden Anhang. Wenn auch manche Autoren, wie Erb und Leyden, bis jetzt noch nicht aus einer gewissen vermittelnden Stellung herausgetreten sind, so neigt doch in neuerer Zeit die Mehrzahl der Neuropathologen und inneren Kliniker der mechanischen

1) Rumpf, Zur Histologie der Nervenfasern und des Axencylinders. Untersuchungen aus dem physiologischen Institut der Universität Heidelberg. Bd. II. 1878.

2) Rumpf, Der Einfluss der Lymphe auf das Centralnervensystem. Pflüger's Archiv. Bd. XXVI. 
Auffassung zu. So schreibt $\left.\operatorname{Strümpell}{ }^{1}\right)^{2}$ ) in seinem Lehrbuch der speciellen Pathologie und Therapie: "Eine derartige " "Compressionsmyelitis"“, d. h. eine durch den Druck als solchen entstandene Entzündung des Rückenmarks, ist schon aus allgemein pathologischen Gründen zu verwerfen, und auch die mikroskopische Untersuchung des Rückenmarks zeigt nichts, was auf eine Entzündung hinweist, und was nicht lediglich die Folge der mechanischen Compression sein könnte". Andere Autoren nahmen den Gedanken einer Gefässcompression zwar auf, liessen diese aber an einem anderen Angriffspunkte als Kahler ansetzen. So legt Ziegler ${ }^{3}$ ) hauptsächlich Werth auf die Druckverengerung der zuführenden Gefässe und betrachtet demgemäss die Erweichung als das Produkt einer Ischämie, einer Ursache, die auch Erb für einzelne Fälle gelten lässt. Immerhin, wie auch die Meinungen hin und her gingen, Kahler gebührt das Verdienst, die Frage wieder neu belebt, unter andere Gesichtspunkte gerückt und damit zu weiteren Versuchen in der eingeschlagenen Richtung angeregt zu haben. Denn noch war vor Allem zweierlei unklar, was den Anatomen und Kliniker nur allzuoft bei der Autopsie überraschte, nehmlich einmal die schon von Kahler beobachtete Thatsache von der Abwesenheit jeglicher Veränderungen trotz deutlicher Delle, und zweitens die manchmal sehr schweren Veränderungen ohne eine Spur von Impression. Schon Kahler hatte auf dem Boden seiner Stauungstheorie Erklärungen dafür versucht, die aber schon aus dem Grunde mangelhaft bleiben mussten, weil sie von Versuchen abstrahirt waren, die den Krankheitsprozessen beim Menschen in vielen Punkten nicht analog waren.

Eine, obschon auch nicht ganz befriedigende lösung der ersten Frage fand Adamkiewicz $)^{5}$ ). Derselbe wies nehm-

1) Strümpell, Lehrbuch der speciellen Pathologie und Therapie. Bd.II. S. 164. Und ähnlich

2) Strümpell, Tageblatt der 59. Versammlung deutscher Naturforscher und Aerzte zu Berlin. 1886. S. 307.

3) Zi iegler, Lebrbuch der spec. pathol. Anat. 7. Aufl. 1892. S. $277 \mathrm{ff}$.

4) Adamkiewicz, Die Lehre vom Hirndruck u. d. Pathologie der Hirncompression. Nach Thierversuchen und Krankengeschichten. Sitzungsber. der Wiener Akad. der Wissensch. 1882 und 1883.

5) Adamkiewicz, Ueber Gehirn- und Rückenmarkscompression beim Menschen. Wiener med. Wochenschr. No. 41 ff. 1887. 
lich nach, dass die nervösen Centralorgane einen gewissen Grad von Compressibilität besitzen, deren Ausnutzung zunächst weder klinisch noch anatomisch irgend welche Spuren hinterlasse. Ein zweiter Grad des Druckes wirke erst molecular, d. h. er mache klinisch Erscheinungen, die aber bei Nachlassen des Druckes wieder verschwänden, und erst ein dritter Grad der Compression führe zu einer wirklichen, irreparablen Zerstörung der Nervensubstanz. Dass in der That die normale Compressibilität der Centralorgane sehr gross sein muss, beweisen ausser der zu ähnlichen Resultaten führenden Arbeit von Albert und Schnitzler') auch klinische Beobachtungen, z. B. ein Fall von Adamkiewicz ${ }^{2}$ ), wo das Hirn eine Geschwulstmasse von $7 \mathrm{~kg}$ (!) ohne nervöse Störungen ertragen haben soll, sowie ein Fall von $\mathrm{Kümmel}{ }^{3}$ ), bei dem die Medulla von einer „reichlich apfelgrossen Geschwulst in einer Ausdehnung von 3-4 cm comprimirt war und sich noch während der Operation von der Compression erholte".

Was nun die Lösung der zweiten Frage anlangt, so konnten die Versuche Kronthal's ${ }^{4}$ ), welcher einem Hunde ein aseptisches Korkstückchen in den Wirbelkanal schob, sowie diejenigen Blumenthal's ${ }^{5}$ ) mit quellenden Laminariastiften theils wegen des allzu geringen Beobachtungsmaterials, theils wegen der unzweckmässigen, viel zu groben Anordnung zu keinem befriedigenden Resultate führen. Auch die schönen Experimente Rosenbach's und Schtscherback's ${ }^{6}$ ) förderten kaum etwas Neues zu Tage. Diese schoben Hunden Silberkügelchen von

1) Albert, E., und Schnitzler, Z., Einige Versuche über Hirndruck. Internat. klin. Rundschau. 1894. No. 1, 2, 3.

2) Adamkiewicz, Wiener med. Wocbenschr. 1887. No. $91 \mathrm{ff}$.

3) K ümmel, Zur Operation der Geschwülste des Wirbelkanals. Archiv für klin. Chir. Bd. XL. S. 452.

4) Kronthal, Zur Pathologie der Höhlenbildung im Rückenmark. Neurol. Centralbl. 89.

5) Blumenthal, Zur Frage der Rückenmarkscompression. Arbeiten der physiologisch-medicinischen Gesellschaft an der Moskauer Universität. 19. December 1888. (Nach einem Referat von Rosenbach.)

6) Rosenbach und Schtscherback, Ueber die Gewebsveränderungen des Rückenmarks in Folge von Compression. Dieses Archiv. Bd. 122. 1890. 
2-4,5 mm im Durchmesser oder Cylinder mit einem Flächendurchmesser von $2 \mathrm{~mm}$ und einer Höhe von $4 \mathrm{~mm}$ in den Rückenmarkskanal und untersuchten das Rückenmark nach verschieden langer Zeit. Bezüglich der histologischen Eigenthümlichkeiten bestätigten sie die Befunde Kahler's: Quellung der Nervenfasern; Vermehrung des interstitiellen Gewebes, Körnchenzellen, aber keine Zeichen einer primären Entzündung. Manchmal fanden sich auch gar keine Veränderungen der weissen Substanz an der Compressionsstelle, dann aber ein "plastischer Erguss" mit consecutiver Spalten- und Höhlenbildung in der grauen Substanz. "Die Gesammtheit der pathologischen Erscheinungen", so resumiren die Verfasser, ,erweckt unwillkürlich den Gedanken einer Beeinflussung des Rückenmarks durch Stauung. In der That macht alles den Eindruck, als ob wir hier das Resultat behinderter Circulation der Cerebrospinalflïssigkeit oder Lymphe in ihren Behältern vor uns haben." War also die ursächliche Stellung des Oedems zu den Veränderungen der Nervenfasern auf's Neue gestützt, so drängte sich nun doppelt die Frage auf: Woher stammen diese relativ grossen Flüssigkeitsmengen?

Denn obwohl es für die Kahler'schen Versuche, bei denen doch immerhin grössere Mengen Wachs injicirt wurden, ja sehr wohl glaublich erschien, dass eine Verstopfung einer grösseren Menge oder stärkerer Aeste von Lymphgefässen stattfinden könnte, so blieb doch durchaus unklar, wie dies z. B. in den Rosenbach-Schtscherback'schen Versuchen schon durch ein einziges, kleines Silberkügelchen hatte geschehen können. Dies veranlasste Enderlen ${ }^{1}$ ), im Anschlusse an seíne Arbeit über die Stichverletzungen im Rückenmark, neue Versuche in dieser Richtung anzustellen. Er brachte Hunden sehr kleine Organstückchen (aseptische Niere) oder Hollundermarkstückchen in den Wirbelkanal und beobachtete auch jetzt degenerative Vorgänge an der entsprechenden Stelle des Rückenmarks. Es musste also auch dadurch schon Oedem hervorgerufen worden sein. Diese auffallende Erscheinung, so meinte Enderlen, liesse sich nicht durch Stauungsvorgänge primärer oder secundärer Art er-

1) Enderlen, Ueber Stichverletzungen des Rückenmarks. Experimentelle und klinische Untersuchungen. Deutsebe Zeitschr. für Chir. Bd. 40. H. 3 und 4 . 
klären. Eben so wenig schien ihm die Annahme eines congestiven Oedems durch Hyperämie an der Operationsstelle, das nach v. Recklinghausen die Filtration von plasmatischer Flüssigkeit durch die Gefässwände erleichtert, oder der Ansammlung eines leicht entzündlichen Oedems, wie es $\mathrm{Schmaus}{ }^{1}$ ) für die Compressionsmyelitis in Folge tuberculöser Wirbelcaries nachgewiesen hat, zur Deutung genügend, und so griff er auf eine experimentelle Thatsache zurück, die Ranvier gefunden hat. Ranvier ${ }^{2}$ ) stelite nach Euderlen's kurzem Referat Versuche über die Bedingungen an, unter denen Oedeme hervorgerufen werden könnten, und machte folgende überraschende Beobachtung. Wenn er Hunden Venenstämme ohne sonstige Iüsionen unterband, so entstand kein namhaftes Oedem, selbst bei so grossen Venen wie der Cava inferior. Erst wenn er z. B. zur Unterbindung der letzteren noch die Durchschneidung des Nervus ischiadicus hinzufügte, entstand ein kräftiges Oedem, das nach einigen Tagen wieder verschwand. Diese Erscheinung beruht, nach Bernard's Experimenten, auf einer Lähmung der Vasomotoren, eine Hypothese, die weiterhin von allen Nachuntersuchern bestätigt wurde. Derartige Vorgänge supponirt Ender len auch für das Zustandekommen grösserer Oedemmengen. Allerdings bleibt hierbei ungelöst, wodurch die Gefässparalyse hervorgebracht wird, und wenn auch, wie Enderlen meint, ganz gewiss "Resorptions- und Organisationsvorgänge" im Spiele sind, so sind wir darüber, welcher Art dieselben sind, vorläufig lediglich auf Vermuthungen angewiesen. Vielleicht handelt es sich um die Einwirkung toxischer Substanzen, die von dem die Krankheit erregenden Körper ausgehen, vielleicht um giftige Zerfallsprodukte desselben, was ja gerade bei malignen Tumoren möglich wäre. $Z u$ berücksichtigen wäre schliesslich auch der Einfluss der zerstörten Nervensubstanz selbst, so dass auf diese Weise eine Art von Circulus vitiosus zu Stande käme. -

Es sei mir nun gestattet, über $\mathbf{3}$ eigene Fälle von Druckdegeneration des Rückenmarks durch Carcinom zu berichten, die im Verlaufe der letzten Zeit zum Theil an der Kgl. med. Klinik,

1) Schmaus, Die Compressionsmyelitis bei Caries der Wirbelsäule. Habilitationsschrift. Wiesbaden 1889 .

2) Die Originalarbeit war mir leider nicht zugänglich. 
zum Theil am Allerheiligen-Hospital in Breslau zur Beobachtung kamen.

\section{Fall I.}

Neugebauer, Heinrich, Bahnarbeiter, 48 Jahre alt.

Anamnese: Die Eltern des Patienten sind an, unbekannter Krankbeit gestorben. Patient selbst weiss über besondere Kinderkrankheiten nichts Näheres anzugeben. Nur soll er im Alter von etwa 6 Monaten längere Zeit rechtsseitigen Ohrenfluss gehabt haben, bald darauf auch eine Anschwellung im rechten Schultergelenk. Dieselbe soll von dem consultirten Arzt eröfnet und viel Eiter entleert worden sein, worauf alle Beschwerden zurückgingen. - Vor mehreren Jahren erlitt Patient einen Bruch des rechten Oberarms, der in seiner Beweglichkeit eine dauernde Einbusse erlitten Lat. - Im Uebrigen war Patient bis vor etwa zwei Monaten nie erheblich krank. Um diese Zeit bekam er eine diffuse Anschwellung an der linken Halsseite; die Bewegungen des Kopfes wurden scbmerzhaft und bescbränkt. Patient suchte die hiesige Kgl. chirurgische Poliklinik auf, wo eine Punction des Tumors vorgenommen wurde. Dieselbe soll eitrige Masse herausbefördert haben. $Z u$ einem grösseren Eingriff konnte sich Patient nicht entschliessen. Allmählich nahm die Anschwellung immer mehr an Grösse zu. Gleichzeitig wurde Patient immer schwächer, so dass er schon seit mebreren Wochen das Bett hüten muss und sich schliesslich anf Anrathen des Arztes in klinische Behandlung begab. Lues nnd Potatorium negirt.

Status praesens: 26. October 1894.

Mittlere Grösse. Knochenbau kräftig. Musculatur schwach entwickelt. Fettpolster zum Theil geschwunden, so dass die Haut in Falten leicht abhebbar ist. Keine Oedeme, kein Exantbem.

Die linke Halsseite ist stark geschwollen, und zwar bandelt es sich um eine diffuse Anschwellung, die hinter dem Musculus sterno-cleido-mastoideus liegt, und deren obere Grenze in der Höhe des äusseren Gebörganges sich findet, von wo sie sich bis fast zur Wirbelsäule erstreckt. Die untere Grenze liegt in der Höhe des Zungenbeins. Die Geschwulst fühlt sich bart an, ist nicht druckempfindlich, zeigt keine Fluctuation. Die Haut über ihr ist zwar leicht gerötbet, aber verschieblich.

Bewegungen des Kopfes sind fast gar nicht möglich. Druck auf die Processus spinosi der Halswirbelsäule ist völlig scbmerzlos, desgleichen auch der Druck auf die vordere Wand der Halswirbelsäule (bei der Untersuchung per os). Auch ist an derselben keine Schwellung nachweisbar.

Lymphdrüsen sind in der linken Achselböble, sowie in der linken Inguinalgegend mehrfach fühlbar.

Gehirnnerven frei.

Pupillen gleich weit, reagiren gleichmässig auf Licht und Accomodation.

Der rechte Oberarm ist verkürzt. An der Aussenseite desselben findet sich eine kleine Narbe. Musculatur des ganzen Armes schwach entwickelt, 
doch wird Flexion, Extension, Pronation und Supination mit einer gewissen Kraft ausgeführt.

Der linke Arm ist gelähmt, besonders der Musculus deltoideus. Flexion und Extension des Vorderarmes sind activ nur wenig möglich. Patient kann mit der linken Hand keine Faust machen oder ihre Finger spreizen.

Die Musculatur der Beine ist geschwächt, aber keineswegs paretisch.

Sensibilität normal. Patient unterscheidet Temperaturdifferenzen, spitze und stumpfe Berübrung, giebt auch annäbernd genau an, wo er berührt worden ist.

Patellar-Reflex vorhanden, rechts etwas schwächer.

Temperatur und Puls normal. Urin sauer, frei von Eiweiss und Zucker.

Hämoglobingelualt des Blutes: $58 \mathrm{pCt}$.

Verlauf.

27. October. Befinden nicht gebessert. Heute Abend Retentio urinae. Daher katheterisirt.

28. October. Befinden unverăndert. Eine genauere (an diesem Tage von Herrn Dr. Mester, weiland Assistenten der medicinischen Klinik, vorgenommene) Untersuchung ergiebt: Parese beider oberer Extremitäten, besonders des Musculus deltoideus der linken Seite - der rechte ist wegen der alten Fractur nicht maassgebend -, sowie des Musculus biceps, der Flexoren des Handgelenks und der Finger. Der M. pectoralis major ist beiderseits frei. Die Rotation des Oberarmes ist nicht genau zu prüfen, da es den Eindruck macht, dass Patient nicht versteht, worum es sich bei diesen Bewegungen handle.

Bauchmusculatur und untere Extremitäten frei. Motorische Kraft erhalten.

- Sensibilität schwer zu prüfen, jedoch an den oberen Extremitäten sicber nicht normal, z. B. die Tastempfindung am Unterarm deutlich herabgesetzt. Schmerzempfindung überall erbalten.

Die Sehnenreflexe der oberen Extremitäten fehlen. Der rechte Patellarreflex fehlt, der linke ist vorbanden.

Die Blase ist bis zum Nabel gefüllt, willkürlich nicht entleerbar. Daher wurde Patient $z$ weimal katbeterisirt.

29. October. Allgemeinbefinden verschlechtert. Parese des linken Armes bat wiederum zugenommen. Beginnende Parese auch der unteren Extremităten. Der Patellarreflex ist auch links verschwunden.

30. October. Patient wird Vormittags in die innere Klinik transferirt und hierselbst folgender Status aufgenommen:

Motilität: Totale Paralyse der oberen Extremitäten. Geringe Schulterbewegung durch Cucullaraction.

Passive Bewegungen der Extremitäten sind schmerzhaft. Stark costale. Athmung (Parese des Z $\mathrm{Z}$ werchfells). Bauchpresse hochgradig paretisch.

Fast gänzliche Paralyse der unteren Extremitäten. Nur geringe Contractionsversuche im Musculus quadriceps und den Extensoren der Zehen, die schon nach einmaliger Ausführung ermüden. Patient kann das rechte 
Bein fast gar nicht, das linke nur wenig von der Unterlage erheben. Das flectirte Bein kann er nicht activ strecken, die Zehen nur wenig bewegen.

Sensibilität: Tast- und Temperaturempfindung bei dem benommenen Zustande des Patienten nicht deutlich festzustellen. Jedenfalls ist sie jetzt auch an den unteren Extremitäten, wenn auch nicht hochgradig, berabgesetzt.

A uf Schmerzeindrücke reagirt Patient nur sehr stumpf. Doch schien oberbalb des Niveaus der 5. bis 6. Rippe die Schmerzempfindung besser za sein.

Sehnenreflexe total erloschen, sowohl der oberen wie der unteren Extremitäten.

Pupillen ohne Differenz, prompt reagirend, mittelweit.

Retentio urinae.

Decubitus am Kreuzbein.

Die Schwellung in der Halsgegend bietet gegen die in der (oben wiedergegebenen) chirurgischen Krankengeschichte verzeichneten Notizen nichts Neues dar.

Urin: Patient wird Abends 6 Uhr katheterisirt und $600 \mathrm{ccm}$ alkalisch reagirenden Urines entleert. Er enthält weder Eiweiss noch Zucker. Im Sediment viel loblensaurer Kalk, wenig harnsaures Ammoniak und Tripelphosphat. Kein Eiter.

Innere Organe ohne Besonderbeiten.

Kein Milztumor.

31. October. Patient war in der Nacht sehr unruhig. Delirien. Sensorium heute Morgen benommen. Jedoch giebt Patient noch Antworten auf die gewöhnlichen Fragen.

Athmung ausschliesslich costal.

Hirnnerven intact.

Beide Pupillen sehr eng, werden auf Lichteinfall nicht enger. (Spinale Myosis mit Pupillenstarre.)

Abdomen besonders im Epigastrium stark aufgetrieben.

Temperatur bis $41^{\circ} \mathrm{C}$. (8 Uhr fräh).

In der Nacht unfreiwillige Stuhlentleerung. Am Morgen ist die Blase nur wenig gefüllt. Es wird daher nicht katheterisirt.

Patient wird in die chirurgische Klinik zurückverlegt und zur Operation des Halstumors geschritten. (Chloroform-Narkose.) Hierbei kamen in der Tiefe bröcklige, weisse Massen zum Vorschein, die nach mikroskopischer Betrachtung mit grösster Wahrscheinlichkeit für Carcinom angesprochen werden konnten. In Folge dessen wurde von einem weiteren operativen Eingreifen abgeseben.

1. November. Unter zunehmender Schwäcbe Exitus lethalis.

Sectionsprotocoll (Herr Prof. Ka ufmann). Grosse, sebr abgemagerte Leiche. Hinter dem oberen Ansatz des Musculus sterno-cleido-mastoideus findet sich eine hübnereigrosse, mit Jodoformgaze ausgefüllte Wundhöble mit frischen Wundrändern. 
Stand des Zwerchfells: beiderseits 5. Rippe.

Lungenspitzen oben leicht verwachsen, sonst frei von Adhäsionen. Nur die linke ist im Bereich der 7. Rippe hinten handbreit an der Wirbelsäule leicht angewachsen.

Herzbeutel weich. Herz sebr schlaff. Rechter Vorbof entbält ebenso wie der linke viel dünnflüssiges Blut. Musculatur rechts graubraun. Wand ziemlich stark von Fett durchwachsen, nahe der Spitze ausserordentlich dünn, links ist die Farbe dunkler. Muskel ausserordentlich schlaff, von Fett durchsetzt und diffus fettig entartet, besonders deutlich an den Papillarmuskeln. Klappen beiderseits ohne Veränderung. Kranzarterien äusserst zart.

Linke Lunge lejcht ödematös, nahe der Spitze ganz minimale schiefrige Induration. Unterlappen etwas hypostatisch. Bronchien weit, mässig mit schleimigem Eiter erfüllt. Bronchialdrüsen stark pigmentirt, sonst ohne Besonderheiten.

Rechte Lunge gleichfalls emphysematös. Die untere Partie enthält wenige, scharf begrenzte, pneumonische Heerde, hier und da Atelektase; die Bronchi sind weit, dünnwandig, stark mit schleimigem Eiter gefüllt. Die Spitze weist eine ganz geringe, linsengrosse Verdickung unter der Pleura auf.

Bei Eröffnung der Bauchhöle liegen zahlreiche, mässig aufgetriebene Darmschlingen vor. Das Duodenum enthält gallig gefärbten Inhalt, der Magen sauer riechenden Brei. Die Schleimhaut desselben ist mit zähem Schleim bedeckt. An der grossen Curvatur, $5 \mathrm{~cm}$ unterbalb der Cardia, findet sich eine fünfmarkstückgrosse, verhärtete Stelle mit unregelmässigem Contour. Dieser Tumor liegt auf einem nach hinten gelegenen Packet harter Lymphdrüsen von Bühnereigrösse, welches auch mit dem Pankreas fest verwachsen ist.

Die Milz ist fest mit der Umgebung verwachsen, klein, faitig, weich. Die Pulpa breiig.

Die Blase ragt sehr stark aus dem Becken heraus, während die Leber ganz unter dem Rippenbogen versteckt ist.

Beim Einschneiden in den Halstumor in der linken oberen Nackengegend zeigt sich, dass derselbe noch weit in die Tiefe hinabreicht. Es wird daher die ganze Halswirbelsäule und ein Stück Occiput in Zusammenhang mit dem Tumor herausgenommen. Es zeigt sich, dass sich derselbe noch weit an den Seiten der Wirbelsäule herumzieht und zwar besonders links. Hierauf wird das herausgenommene Stück in sagittaler Richtung so durchsägt, dass der Schnitt neben dem Rückenmark verläuft und dasselbe intact lässt. Man bemerkt nun, dass der Tumor einen starken Fortsatz zwiscben Atlas und Epistropheus in den Wirbelkanal entsendet und in demselben als ein Strang von etwa $4 \mathrm{~cm}$ Länge in fester Verwachsung mit dem Ligamentum longitudinale posterius hinabzieht. Der Körper des Atlas und Epistropheus, sowie noch ein Theil des 3. Halswirbels sind von denselben grauröthlichen Massen durchsetzt, aus denen der Tumor besteht. Ferner sieht man, dass auch durch die Intervertebrallöcher der ersten drei Halswirbel Tumormassen sich gegen den Wirbelkanal vorschieben. 
Auf einem Quersägeschnitt zwischen dem 3. Halswirbel und Epistropheus zeigt sich, dass die blasse Dura auch auf ihrer Innenseite von markigen Auflagerungen bedeckt ist. Dieselben setzen sich aber nicht auf die Pia fort. Der Rückenmarksquerschnitt erweist sich besonders links vorn durch den nach unten wucbernden Strang stark comprimirt, etwas weniger durch einen dünneren Strang links seitlich. Die Rückenmarkssubstanz ist im Bereich der Compression etwas weicher wie normal. Das Querschnittsbild ist dabei deutlich zu sehen. Es erscheint nach links verschoben.

Diagnose: Carcinoma scirrhosum ventriculi. Carcinomatosis glandularum cervicalium sin. part. in carum vertebrale progrediens. Malacia alba medullae spinalis in partecervical. sup. - Oedema leve pulmonum. Bronchitis diffusa catarral. Parvitas cordis.

Das Rückenmark wurde nach mehrmonatlicher Aufbewahrung in Müller'scher Flüssigkeit in Spiritus von aufsteigender Concentration nachgehärtet, in einzelne, nicht mehr als $0,5 \mathrm{~cm}$ betragende Segmente zerschnitten, in Celloidin eingebettet und auf dem Mikrotom geschnitten. Die höchstens $20 \mu$ dicken Schnitte wurden entweder nach der von $\mathrm{Pal}$ angegebenen Modification der Weigert'schen Methode oder mit neutralem Carmin gefärbt. Als brauchbar erwiesen sich natürlich auch die anderen in der Rückenmarkshistologie üblichen Methoden, z. B. auch die Färbung nach van Gieson. Sehr schöne Bilder erhielt ich auch durch eine Abänderung dieser Methode in der Weise, dass ich statt mit Hämatoxylin, mit Nigrosin vorfärbte, wodurch man auch das 24 stündige Wässern umgeht. -

Ehe ich nun an die Besprechung der Querschnittsbilder gehe, möchte ich mir eine Vorbemerkung erlauben, die auch für meine übrigen Fälle Geltung hat. Ich habe es nehmlich für ermüdend und entbehrlich erachtet, jedes einzelne Segment, das thatsächlich zur Verarbeitung kam, zu beschreiben. Denn bei der geringen Dicke der Segmente konnte naturgemäss nicht jedes einzelne bemerkenswerthe Veränderungen gegen das vorhergehende aufweisen. Es sei mir daher gestattet, die zusammengehörigen Segmente zusammenzufassen und so etappenweise die interessanten Befunde zu verzeichnen, die das Querschnittsbild in den verschiedenen (jeweils angegebenen) Wirbelhöhen darbietet, und zwar soll zunächst vorzugsweise die Topographie der Degenerationsgebiete, wie sie schon makroskopisch, besonders am Müller'- 
schen Chromsalzpräparat, deutlich zu sehen ist, eingehende Berücksichtigung finden, während wir uns den feineren histologischen Details erst später in einem besonderen Abschnitt zuwenden wollen. Hinzufügen will ich noch, dass jeder makroskopische Befund durch die mikroskopische Untersuchung controlirt und erweitert wurde. -

Es ergaben sich nun folgende Resultate:

$$
\text { Höhe des Atlas (I, C } 1 \text { ). (Taf. XI. Fig. I.) }
$$

Das ganze Querschnittsbild ist am Müller-Präparat heller als ein in derselben Flüssigkeit conservirtes normales Präparat aus dieser Höhe. Besonders hell jedoch erscheinen in den Hintersträngen $z$ wei, von der Mitte der Hinterhörner neben diesen bis zur Peripherie verlaufende Degenerationsstreifen. Dieselben sind etwa ebenso breit wie die Hinterhörner und nur durch einen ganz schmalen Streifen etwas dunkleren Gewebes von ihnen abgesetzt. Sodann finden sich zwei, in ihrem dorsalen Theile durch einen kleinen, dreieckigen dunkleren Bezirk getrennte Degenerationsstreifen neben der Fissura posterior. Sie beginnen etwas oberhalb der Mitte derselben und treffen sich dann an der Grenze zwischen dem mittleren und ventralen Drittel neben der Fissur. Fernerhin heben sich auch die Kleinhirnseitenstrangbahnen durch etwas hellere Färbung ab. Ausserdem finden sich noch zahlreiche, heerdweise verstreute hellere Fleckchen, besonders in den Hintersträngen, weniger in den Seitenstrangbahnen, sowie, bei mikroskopischer Betrachtung, zahlreiche, vereinzelte, über den ganzen Querschnitt verbreitete degenerirte Axencylinder.

Die graue Substanz ist nicht ganz deutlich und zeigt mikroskopisch auffallend wenig Ganglienzellen.

Im Uebrigen bestätigt die mikroskopische Untersuchung, dass Hinterund Seitenstränge, in diesen besonders ein kleiner, dem Hinterhorn angelagerter Bezirk des linken Seitenstranges, von schwerer Degeneration ergriffen sind.

Körper des 2. Halswirbels:

Wie schon ans dem Sectionsprotocoll erhellte, war dieser Theil des Rückenmarks am meisten gefährdet. Dementsprechend finden wir denn auch hier die schwersten und unregelmässigsten Veränderungen.

Oberer Theil des 2. Halswirbelkörpers $\left(\mathrm{C}_{2 \mathrm{a}}\right)$.

Das Querschnittsbild ist durchaus asymmetrisch. Während nehmlich die rechte Seite halbkreisförmig aussieht, ist die linke, besonders im ventralen 
Theile stark abgeplattet und wie im Ganzen nach unten gedrückt. Dass diese Asymmetrie hauptsächlich durch die andrängenden Tumormassen, welche Fig. $\mathrm{I}, \mathrm{C}_{2}$ a nach dem dazu gehörigen Schnitte mitaufweist, hervorgerufen ist, ist wohl zweifellos. Jedoch erscheint mir auch beachtenswerth, dass die linke Seite trotz der Compression immer noch etwas voluminöser erscheint, als die rechte, was wohl auf eine stärkere ödematöse Durchtränkung zurückzuführen sein dürfte. Das Colorit des Querschnitts im Ganzen ist überaus hell. Auf diesem hellen Grunde heben sich noch besonders hellgelbe Einsprengungen hervor, die unregelmässig äber den ganzen Querschnitt verstreut sind. Sie finden sich besonders zahlreich in den Hintersträngen, sowie dem der Tumorseite entsprechenden Seitenstrange. Dass sich auch hier bei mikroskopischer Betrachtung noch überall einzelne oder in kleinen Gruppen zusammenstehende degenerirte Axencylinder vorfinden, ist ja fast selbstverständlich.

Medial von den Hinterhörnern findet sich anch hier, obsehon nicht so ausgesprochen, die im vorigen Querschnitte beschriebene dreieckige Degenerationszone.

Auch die graue Substanz ist unsymmetrisch. Das linke Hinterborn ist etwas verdünnt, lateralwärts ausgezogen und nach dem Hinterstrange zu leicht ausgebuchtet. Sein Contour ist nicht ganz deutlich. Mikroskopisch findet sich eine entschiedene Verminderung der das Filzwerk der grauen Substanz bildenden Nervenfasern, sowie an den Ganglienzellen diejenigen Veränderungen, welche meist als Zeichen von Degeneration angesehen werden, wie schlechte Färbbarkeit des Zellprotoplasmas, des Kernes, Pigmentation u. a.

\section{Unterer Theil des 2. Halswirbelkörpers $\left(\mathrm{C}_{2 \mathrm{~b}}\right)$.}

Dieser Querschnitt zeigt die Veränderungen auf ihrer Höhe. Wie Fig. I, $C_{2 b}$ darstellt, pressen die gegen den letzten Querschnitt noch vermehrten Tumormassen die ganze linke Rückenmarkshälfte gewissermaassen schiffskielartig zusammen. Besonders stark ist ihre ventrale Seite abgeplattet, ja sie verläuft sogar in einer centralwärts leicht convexen Linie. Dieser Deformirung ist auch die graue Substanz gefolgt. Dieselbe ist zunächst links nicht so deutlich abgegrenzt als rechts. Das linke Vorderhorn ist verschwommener und kleiner als das rechte und bildet mit dem Hinterhorn einen spitzeren Winkel, als dies rechts der Fall ist. Das linke Hinterhorn läuft dem ventralen Peripheriecontour etwa parallel, ist lang ausgezogen und weist hinterstrangwärts eine leicht concave Ausbuchtung auf.

Wie im vorigen Querschnitt finden sich auch hier sehr zahlreiche, 
über den "ganzen Querschnitt verstreute Heerde stark degenerirter Nervenfasern, sowie einzelne derartige Elemente.

In der grauen Substanz zeigen sich dieselben Veränderungen, wie im vorigen Segment.

Hie und da sind stark gefüllte Gefässe anzutreffen. Jedoch möchte ich schon hier an diesem am schwersten geschädigten Querschnitte hervorheben, dass ich durchaus keine Spuren einer ächten Entzündung entdecken konnte.

\section{Mitte des 3. Halswirbels $\left(\mathrm{C}_{3}\right)$.}

Das Querschnittsbild ist gegen das vorige überraschend gut erhalten. Dieser geringen verticalen Ausdehnung der schweren Veränderungen werden wir, wie ich vorwegnehmen möchte, anch in den anderen Fällen begegnen. Sie scheint also eine constante Erscheinung zu sein, deren auch Gowers ${ }^{1}$ ) Erwähnung thut. -

Zunächst besteht gar keine Asymmetrie: Beide Seiten sind durchaus gleich contourirt und auch in ihrer Binnenzeichnung gleich deutlich. Ein weiterer, wichtiger Unterschied ist das Fehlen der heerdförmigen Degeneration. Es findet sich makroskopisch vielmehr lediglich eine Degeneration der Seitenstränge und zwar des linken mehr als des rechten. Mikroskopisch. zeigt sich, dass ausser in den soeben erwähnten Bezirken auch die Vorder- und Hinterstränge degenerirte Nervenfasern, in den letztgenannten hie und da zu kleinen Gruppen zusammenstehend, aufweisen, sowie nebenbei natürlich sonst im Querschnitte noch vereinzelte zerstreute degenerirte Nervenfasern.

In der grauen Substanz sind sichere pathologische Veränderungen schwer nachzuweisen, aber jedenfalls in geringem Maasse vorhanden.

In den folgenden Segmenten (vergl. die Figuren $\mathrm{I}_{,} \mathrm{C}_{4}$ bis $\mathrm{D}_{\tau}$ ) ändern sich diese soeben beschriebenen Verhältnisse nur insofern, als bereits in der Höhe des 5. Brustwirbels die Degeneration der Vorderstrangbahnen verschwunden ist. Hingegen war die Seitenstrangentartung, wenn auch von Segment zu Segment in stetig abnehmender Intensität, noch bis zum 7. Brustwirbel einschliesslich zu verfolgen.

Fassen wir die Veränderungen, die wir demnach im Verlaufe dieses Rückenmarks beobachtet haben, noch einmal kurz zusammen, so zeigt sich, dass wir es, abgesehen von den fleckförmigen Degenerationsheerden an der Compressionsstelle, bezw.

1) Gowers, Handbuch der Nervenkrankheiten. Autorisirte deutsche Ausgabe von Dr. Carl Grube. 1892. Bd. I. S. 353. 
ihrer Umgebung, hauptsächlich mit einer aufsteigenden Entartung der Kleinhirnseitenstrangbahnen, sowie eines kleinen Bezirks in den Burdach'schen Strängen (bis zum obersten Halsmark), mit einer absteigenden Entartung der Vorderstrangbahnen bis zum 4. Brustwirbel, der Pyramidenseitenstränge bis zar Mitte des Dorsalmarks zu thun haben.

Fall II.

Gottschlich, Hermann, Cigarrenarbeiter, 42 Jahre alt.

An amnese: Hereditäre Belastung nicht nachweisbar. Ausser Masern im Kindesalter will Patient selbst nie eine Krankheit gehabt haben.

Seit Ende Januar dieses Jahres Jiegt er an "Lungenkatarr" - starker Husten mit reichlichem Auswurf - zu Bett. Doch befand er sich nach arrtlichem Urtheile bereits auf dem Wege zur Besserung. Am 10. Februar, Sonntag, wollte Patient, der sich wieder wohl befand, aus dem Bette aufstehen, fiel aber plötzlicb um und bemerkte beim Versuch, sich wieder zu erheben, dass beide Beine gelähmt waren, jedoch nicht völlig, sondern nur so weit, dass er sich immerhin wieder aufrichten konnte, wenn er sich mit den Bänden an Gegenständen festhielt. Montag Abend konnte er auf einmal seine Blase nicht mehr entleeren, obwohl er spürte, dass es nöthig war. Etwas Aehnliches ist seit vorgestern mit dem Stuhl der Fall. Patient merkt z. B. ganz deutlich das Andrängen der Winde, ohne sie willkürlich gleich geben lassen zu können. Der Zustand der Beine ist bisher unverändert geblieben. Nach Aussage des Patienten haben Bewusstlosigkeit, Schwindel und Kopfschmerzen nie bestanden. Eben so wenig Erbrechen. Jede venerische Infection bestritten; kein Alkoholabusus. Cigarren: Zu 5 Stück pro die mittlerer Stärke.

Die Aufnahme in die Kgl. medicinische Klinik erfolgte am 13. Februar 1895.

Status praesens: 13. Februar 1895.

Erheblich abgemagertes Individuum. Blässe der Haut und sichtbaren Schleimhäute. Ueberall starke Behaarung. Keine Oedeme, kein Decubitus. Sonst keine Veränderungen an der Haut, die nirgends glänzend ist oder oberfächliche Abschilferungen zeigt.

Sensorium frei.

Wirbelsäule ohne Deformität. Hirnnerven ohne nachweisbare Störungen.

Die oberen Extremitäten zeigen keine Spur von Parese oder Ataxie. Ebenso ist die Musculatur des Schultergürtels, sowie an Brust und Bauch intact.

Die unteren Extremitäten sind beide mässig paretisch und zwar das rechte in etwas höherem Grade als das linke. Relativ am kräftigsten functioniren noch der Musc. ileo-psoas und quadriceps. Eine totale Lähmung besteht nirgends. 


\section{4}

Blase: Willkürliche Entleerung unmöglich. Daher Katheterismus. Urin: sauer, frei von Eiweiss. Reducirt bis zur Braunfärbung. (Sehr concentrirt.)

Stuhlgang: obstipirt. Nur auf Einläufe und Laxantien.

Sensibilität: Nirgends gröbere Störungen. Auch in der Gegend des Dammes keine Veränderung der Sensibilität nachweisbar. Gefühl für die Entleerung von Blase und Mastdarn erhalten.

Patellarreflex beiderseits vorhanden, leicht auszulösen; ebenso der Achillessehnenreflex. Die Plantarreflexe fehlen beiderseits. Desgleichen die Cremaster- und Abdominalreflexe.

14. Februar 1895. Bei der genaueren Sensibilitätsprüfung ergab sich abweichend von den gestrigen Resultaten:

Herabsetzung der Schmerz- und Temperaturempfindung links in einem Bezirk, der sich etwa von der Mitte des linken Oberschenkels bis fast in Nabelböhle (3 Finger breit unterbalb) hinauferstreckt und nach innen mit der Medianlinie abschneidet. Kalt und warm werden in diesem Gebiet häufig mit einander verwechselt. Am Rüeken besteht von dem Processus spinosus des untersten Brustwirbels an nach abwärts etwas vermehrte Druckempfindlichkeit.

16. Februar. Die Bewegungsunfähigkeit hat im Bereich der paretischen Muskeln noch etwas zugenommen, obne sich răumlich weiter ausgebreitet zu haben. Patient kann heute z. B. die Beine nur wenig von der Unterlage entfernen.

Sensibilităt wie früher. Auch unterhalb der Kniegelenke besteht beiderseits Hypästhesie für Berührung.

Blase wie früber. Täglicher Katheterismaus.

Urin sauer, ohne Eiweiss.

Viel Husten. Geringe Expectoration. Sputum eitrig-katarrhalisch.

Lungen: Diffuse Bronchitis. Rechts vorn oben in der Supraclavieulargrube bronchiales Exspirium.

20. Februar. Noch weitere Zunahme der Lähmung. Patient kann jetzt nur noch Andeutungen von Bewegungen ausführen.

Patellarreflexe schwach; die übrigen Reflexe wie früher.

Die Sensibilităt jst von Nabelböhe an jetzt deutlich verändert, am stärksten bis gegen das untere Viertel der Oberschenkel hin, wo beiderseits Herabsetzung für Berührung bestebt. Die Schmerzempfindung ist an den unteren Extremitäten durchweg stark vermindert. Ebenso die Kälte- und Wärmeempfindung.

Blase und Mastdarm wie früher.

Diffuse Bronchitis. Sputum obne Tuberkelbacillen.

Beginnender Decubitus.

23. Februar. Ernsterer Zustand. Temperatur 38,6. Leichter Decubitus am Kreuzbein. Respiration 30, Puls 120.

Lungen: Rechts binten oben und links hinten oben kürzerer Schall, bronchiales Exspirium. Jedoch ist auch in der Nähe durchweg weit fortgeleitetes bronchiales Athmen zu bören. 


\section{5}

Völlige Paralyse der unteren Extremitäten.

Auch die Schwäche der Bauchpresse ist deutlicher.

Blase: Retentio urinae.

Urin: sauer. Ohne Besonderheiten.

Sensibilität: Der Tastsinn ist an den Füssen, den Unter- und Oberschenkeln bis zur oberen Grenze des unteren Drittels herabgesetzt, nirgends erloscben. Die Schmerzempfindung ist sehr vermindert. Selbst starke faradische Ströme werden von den Fusssohlen bis zum Nabel nicht sehmerzhaft empfunden. theilt.

Kälte- und Wärmesinn sind ähnlich wie die Schmerzempfindung ver-

Entartungsreaction besteht nirgends.

Patellarreflexe schwach.

Hautreflexe fehlen.

24. Februar. Status idem. Temperatur 40,1. Puls 144. Respiration 42.

Lungen: Rechts binten unten und links hinten unten nahe der Wirbelsäule Dämpfung, Rasselgeräusche, kein bronchiales Athmen. Rechts und links binten oben Scballverkürzung und bronchiales Exspirium. Rechts vorn oben oberhalb der Clavicula verkürzter Schall und bronchiales Athmen.

Lähmung und Sensibilitätsstörungen wie gestern.

Sensorium frei.

25. Februar. Exitus lethalis.

Auch im letzten Sputum keine Tuberkelbacillen.

Urin enthielt zeitweilig etwas Eiweiss, sonst nichts Pathologisches. Sein specifisches Gewicht war etwas hochgestellt, 1017-1022.

Soctions-Protocoll. (Herr Geheimrath Prof. Dr. Ponfick.) Sehr grosser, schwach musculöser Mann.

Brust flach. Bauchdecken schlaff.

Zwerchfellstand rechts am unteren Rand der 5. Rippe, links am oberen Rand der 6. Rippe. Rippenknorpel fast durchweg verkalkt.

Bei Eröffnung der Brusthöhle zeigt sich das Gewebe des Mediastinum anticum besonders über den grossen Gefässen mit zahlreichen markigen Erhebungen besetzt, die sich auf die äussere Fläche der Pleura pericardiaca in grosser Ausdehnung fortsetzen und ziemlich unmittelbar zu einer höckrigen Anschwellung in der Gegend des Hilus der rechten Lunge überleiten. Der recbte Oberlappen ist sehr angeschwollen, hinten mit der Pleura costalis kaum trennbar verwachsen. Beim Versuch, Lungen und Halsorgane herauszunehmen, reisst die Lunge hinten ein. Hier ist das Gewebe mit grauweissen, markigen Massen erfüllt, die sich vielfach in Gestalt kleiner Höcker und Körner vordrängen. Abgesehen von der Adbäsionsstelle ist die Pleura mit graugelbem Belage bedeckt, der sich leicht ablösen lässt. Der Oberlappen ist voluminöser als normal und siebt bunt aus. Hier wechseln nehmlich grauweisse, markige Einlagerungen mit schiefrigen Zügen lose verdichteten Lungengewebes mannichfach ab. Dazwischen bemerkt man schmutzig-graugelbe, locker fetzige Heerde und da und dort kleine Hohl- 
räume, die mit locker baftenden Trümmern des zerfallenden markigen Gewebes erfüllt sind. Gegen den unteren Rand werden die zerfallenden Bezirke umfänglicher. Das $Z$ wischengewebe ist fester hepatisirt, fast ganz luftleer.

Fauces, Pharynx, Larynx, Trachea frei.

Erst im rechten Bronchus, allerdings unmittelbar nach dessen Abgang, beginnen sich in der dunkelrothen Schleimbaut mehrere, immer reichlicher werdende Körner herauszuheben. Von da aus setzen sich derartige Körnungen unter zunebmonder Verengerung des Lumens mebrere Centimeter weit fort, bier auch in die einzelnen Verzweigungen weiter dringend, - bis zuletzt die Lichtung fast ganz verlegt ist. An dieser Stelle geht die Infiltration der Bronchialwand fast unmittelbar in die geschilderten pulmonalen Heerde über. Auch erfüllt sie die Wandungen der da und dort quergetroffenen Blutgefässe, deren Lumen ebenfalls mebrfach verengt ist. Die Bronchialdrüsen sind stark vergrössert und geben unmittelbar in die geschilderte, am medianen Rande des rechten Oberlappens und auf der Pleura pericardiaca vorbandene Geschwulstmasse über. Weiterhin werden auch die grossen Venen der Brustapertur davon erfasst, besonders die V. cava superior und beide Venae anonymae, schliesslich aber auch die Centralbezirke der Jugularis und Subclavia dextra. Die Lichtung der letzteren ist durch mehrere grauröthliche, markige Knoten etwas beengt, aber doch noch von glatter Intima überzogen. Nach hinten von der Pleura costalis sieht man gleiche markige Wucherungen in den Intercostalmuskeln, den Rippen knollig aufgesetzt und auch in's Periost vordringend. Ferner betheiligen sie auch die Processus transversi und schieben sich allem Anseheine nach durch die Foramina intervertebralia in die Rückenmarkshöhle, den Zusammenhang mit jener intervertebralen Wucherung continuirlich herstellend.

Nach dem Aufmeisseln des Wirbelkanals von binten zeigt sich im unteren Theil der Halswirbelsäule an der vorderen Fläche der Processus spinosi ein graurötblicher Belag von mindestens $\frac{1}{2} \mathrm{~cm}$ Mächtigkeit mit starken Injectionen und Gefässbildung. Weiter abwärts ziebt sich eine mehr gelbe, graue, feste Masse äbnlicher Art hin, die sich durch die ganze Höhe des Brusttheils hinabziebt, überall mit lebhafter Injection. Im LumbaltheiI ist nur abnorm reichliches Fettgewebe zu entdecken. Vor dem Herausnehmen des Rückenmarks sieht man noch auf der hinteren Duraflächo auf $2-3 \mathrm{~cm}$ Länge eine markige Auflagerung von etwa $\frac{1}{2} \mathrm{~cm} \mathrm{Mächtigkeit.} \mathrm{Sie} \mathrm{lässt}$ sicb von der Unterlage nicht abtrennen, findet jedocb an der Dura so vollständige Schranken, dass an der Innenfiache nicht die geringsten. Veränderungen erkennbar sind.

Auch am übrigen Theil der Dura lässt sich von innen nicht einmal stärkere Blutfülle wahrnehwen. Im Bereich der Auf lagerung ist das Räckenmark schmäler, indem ron links eine flache, curvenartige Einschneidung bemerkbar ist. Doch ist die Pia auch hier ganz normal.

Selbst auf Querschnitten, die von der oberen Fläche ab bis jenseits der verdünnten Partie gelegt werden, sieht man nirgends abnormen Blut- 
gehalt. Auf dem Durcbschnitt zeigt sich die Rückenmarkssubstanz im Bereich der verschmälerten Partie, deutlicher noch unterhalb derselben, leicht aufgequollen. Die weisse Substanz ist leicht gallertig, feucht, fein grau gesprenkelt, die Gefässo etwas stärker gefüllt. Keine Blutungen.

Im weiteren Verlauf ist das Rückenmark ganz normal und wird nicht weiter aufgeschnitten.

Milz: etwas vergrössert. Pulpa dunkelrotb, etwas vorquellend. - Follikel gross und deutlich.

Nebennieren: Rinde fleckig, gelblich, sehr blass.

Nieren: venös, hyperämisch, leicht vergrössert. An einem Markkegel der linken Niere ein stecknadelkopfgrosser Heerd yon grauweisser Farbe.

Magen und Darm: ohne Besonderheiten.

Leber: allgemein etwas vergrössert. Nabe dem vorderen Rande des linken Lappens sieht man einen grauweissen Knoten mit nabelförmiger Einziehung in der Mitte und lebhafter Gefässneubildung von $3 \mathrm{~cm}$ Durchmesser. Aehnliche, aber kleinere, finden sich zerstreut noch im linken und rechten Lappen. Im Parenchym sind die hellgraubraunen Acini undeutlich und klein. Auch auf dem Durchschnitt bemerkt man einige grauweisse Heerde, die freilich meist nur erbsengross sind, dabei aber sebr starke Gefässneubildung zeigen, so dass die Schnittfäche zum Theil fast teleangiektatisches Aussehen bietet.

Gallenblase und -wege frei.

Harnblase: stark erweitert.

Schleimbaut leicht geröthet. Urin sauer riechend, leicht getrübt, mit etwas Jodoform untermischt.

Schädel auffallend stark, kurz und breit. Das Os frontale ist sehr dick, entsprechend einer riesigen Entwickeiung der Sinus frontales, in deren oberem Umfang der Schädel $1,4 \mathrm{~cm}$ dick ist, obwohl die Sägelinie eher oberbalb als unterbalb der gewöhnlichen Linie verläuft. Es wird dies nur dadurch erklärbar, dass der Sinus sich bis in das Bereich der Tubera frontalia vorschiebt. Dieser obere Abschnitt misst $1 \mathrm{~cm}$, der untere $3,9 \mathrm{~cm}$, in der Länge $3,8 \mathrm{~cm}$. In der Breite jedoch scheint er sich unten lateralwärts auszudehnen. Der Hohlraum ist durch eine Reihe schmaler knöcherner Leisten etwas gesondert. -

Es sind also Schädeldach und Gebirn fast so lang wie breit. Ersteres hat desbalb ein schüsselförmiges Aussehen, letzteres ist fast rund. Auf der Oberfäche der rechten Hemisphäre findet sich ein lockerer, brannrother Belag grösstentbeils flüssigen oder geronnenen Blutes, der durch kräftigen Wasserstrahl abspülbar ist. -

Die Pia ist frei von Bluterguss. Die Hirnsubstanz ist derb und dem Anscheine nach ganz frei. Die Seitenventrikel sind nicht erweitert.

Gefässe und Nervenwurzeln ohne Besonderheiten.

Diagnose: Carcinoma medullare bronchi dextricum stenosi. Infiltratio carcinomatosa lobi sup. fere totius cum gangraena incipiente disseminata. Carcinomatosis glandulariambron- 


\section{8}

chial. et mediastinal. Carcinomatosis miliaris pleurae et pericardii. - Pleuritis fibrinosa later. sin. recens. - Infiltratio carcinomatosa musculorum intercostalium II. usque IV. in cavum intervertebrale progrediens. - Malacia alba medullae spinalis in parte dorsali sup. - Oedema leve pulmonum. Parvitas cordis. - Stenosis venarum thoracic. imprimis subclaviae dextr. - Hyperplasia lienis recens. - Dilatatio vesicae urinariae. - Carcinomata disseminata hepatis. -

Das Rückenmark dieses Falles, das mir von der Höhe des letzten Halswirbels bis etwa zur Lendenwirbelsäule zur Verfügung stand, wurde mehrere Monate lang in Müller'scher Flüssigkeit aufbewahrt und dann in derselben Weise wie das erstbeschriebene weiterbehandelt.

Die Untersuchung der Querschnittsbilder der auf einander folgenden Segmente ergab Folgendes:

Höhe des 7. Halswirbels, oberer Theil (II, $\mathrm{C}_{7 \mathrm{a}}$ ).

Es zeigt sich am ungefärbten Müller-Präparat eine deutliche hellere Verfärbung der Goll'schen Stränge. Die entartete Partie bildet eine genau symmetrische kegelförmige Figur, die mit ihrer etwas abgestumpften Spitze bis an die hintere Commissur heranreicht. Ihre Basis liegt zwischen den beiden hinteren. Längsfurchen. Sie besitzt auf jeder Seite einen deutlichen (ausspringenden) ventralen und (einspringenden) dorsalen Winkel. Der Scheitel des ersteren liegt in der Höhe der Substantia gelatinosa Rolandi, etwas oberhalb der vorspringenden medialen Ecke der Hinterhörner, der des letzteren etwas oberhalb der Höhe des Austritts der hinteren Wurzeln. Peripheriewärts wird die Degeneration schwächer. Zwischen diesem grossen Degenerationsgebiet tritt deutlich ein minder heller, zu beiden Seiten der Fissura posterior hinlaufender, biconvexer, spaltförmiger Bezirk hervor, der etwa an der Grenze von ventralem und mittlerem Drittel der Fissur beginnt und in die eben erwähnte peripherische Zone geringerer Degeneration mündet.

Interessant sind fernerhin zwei dünne, von dem Scheitel des ventralen Winkels sich abzweigende hellere Degenerationslinien, die dentlich von dem Hauptdegenerationsstrange durch eine Zone dunkleren, also weniger degenerirten Gewebes geschieden sind und denselben als flügelartige feine Ausläufer bis etwa zum Scheitel des dorsalen Winkels begleiten.

Ausserdem findet sich noch eine geringe, aber deutliche Degeneration der Kleinhirnseitenstrangbahnen.

Mikroskopisch zeigen sich in der hellen Partie sehr zahlreiche degenerirte Axencylinder, erweiterte und stark gekräuselte Mark- 
scheiden, sowie zahlreiche erweiterte Lymphräume. Weit weniger häufig finden sich diese Veränderungen in den Kleinhirnseitenstrangbahnen und dem ventralen Abschnitte der Burdach'schen Stränge, sowie in dem soeben beschriebenen, der Fissura posterior anliegenden spaltförmigen Bezirk. Schliesslich finden sich noch hie und da vereinzelte degenerirte Axencylinder ohne besondere Anordnung in der weissen Substanz.

Die sonstigen histologischen Einzelheiten werden später in dem schon oben erwähnten besonderen Abschnitte eingehend Besprechung finden.

Höhe des 7. Halswirbels, unterer Theil $\left(\mathrm{C}_{7 \mathrm{~b}}\right)$.

Die Entartungsfigur der Hinterstränge bietet in toto kaum Nenes. Nur zeigt sich, dass das ventrale Ende nicht mehr stumpf, sondern, leicht pilzförmig nach beiden Seiten verbreitert, die Commissura posterior noch eine Strecke weit, fast bis zum Beginn der Hinterhörner begleitet, wo sich die Enden allmählich verjüngen und in eine scharfe Spitze anslaufen. Ferner sind auch die mehr dorsalwärts gelegenen Partien der Goll'schen Stränge stärker afficirt, so dass sie sich weit weniger wie im vorigen Segment von den ventralen unterscheiden.

Höhe des 1. Brustwirbels, oberer Theil $\left(D_{1 n}\right)$.

Die Entartungsfigur der Hinterstränge ist im Ganzen etwas plumper geworden; sie ist mehr flaschenförmig, ohne die scharfen, eckigen Contouren. Das ventrale Ende der Figur ist in dem Sinne etwas verbreitet, dass die Höhe des Pilzkopfes zugenommen hat. Fernerhin sind die flügelartigen Fortsätze zu beiden Seiten der Entartungsfigur verschwunden. Hingegen besteht zwischen den stark degenerirten Goll'schen Strängen noch deutlich die dunklere spaltförmige Figur fort und scheint nach der Peripherie hin dreieckig auszulaufen.

Die Kleinhirnseitenstrangbahnen sind hier deutlicher als in den vorhergehenden Segmenten degenerirt. Die mikroskopische Untersuchung bestätigt im Wesentlichen das makroskopische Bild.

Höhe des 1. Brustwirbels, unterer Theil $\left(D_{1 b}\right)$.

Allmählich wird die Entartungsfigur immer plumper, bis sie schliesslich vom centralen bis peripherischen Ende fast gleiches Caliber hat, und von dem pilzförmigen Kopfe am ventralen Ende kaum noch eine Andeutung besteht.

Auch das dorsale Ende ist stark verbreitert, so dass es fast bis an die Hinterhörner heranreicht. Die in den vorigen Querschnitten erwähnte, meist recht undeutliche Partie geringerer Degeneration zwischen den stark degenerirten Goll'schen Strängen ist gerade noch constatir- 
bar. Hingegen besteht eine schon makroskopisch sehr ausgesprochene Degeneration der Kleinhirnseitenstrangbahnen.

Höhe des 2. Brustwirbels, oberer Theil $\left(D_{2 a}\right)$.

Die Entartungsfigar der Hinterstränge ist nunmehr so verbreitert, dass sie nur noch einen schmalen Saum an den Hinterhörnern frei lässt, also den grössten Theil der Burdach'schen Stränge mitumfasst. Ihre Gestalt ist nicht mehr pilzförmig, sondern plump bisquitförmig, und zwar liegt die mittlere Einschnürung in der Höhe der Substantia gelatinosa Rolandi. Nach der Peripherie hin nimmt die Intensität der Degeneration beträchtlich ab.

Die noch im letzten Segment sichtbare, spaltförmige $Z$ wischenhinterstrangszone, wie wir sie nennen möchten, ist fast gänzlich verschwunden, während wiederum eine ziemlich ausgesprochene Kleinhirnseitenstrangdegeneration besteht.

Die graue Substanz war makroskopisch noch ganz deutlich. Mikroskopisch schienen die Ganglienzellen stark vermindert. So zählte ich in einem Präparate kaum 4 bis 5 in jedem Vorderhorn, und diese Zahlen wurden auch in den anderen Präparaten nicht wesentlich überschritten.

Höhe des 2. Brustwirbels, unterer Theil (D2b).

Der Querschnitt ist zunächst im Ganzen heller als der vorige.

Sodann fallen durch starke Degenerationen die Hinterstränge in die Augen. Diese degenerirten Partien haben zwar in toto etwa die Gestalt wie im vorigen Querschnitt, zeigen aber nicht dieselbe geschlossene Gestalt und gleichmässig helle Farbe, sondern sind mehr fleckweise verfärbt, so dass sich eine gesprenkelte Zeichnung ergiebt. Solche Sprenkelung findet sich nicht nur in den Hintersträngen, sondern auch, allerdings weit schwächer, im rechten Seitenstrang. Ueberhaupt scheint die ganze rechte Seite stärker ergriffen zu sein. Auch die graue Substanz ist auf derselben entschieden undeutlicher als auf der linken.

$$
\text { Höhe des 3. Brustwirbels, oberer Theil (Da). }
$$

Es zeigt sich an diesem Querschnitt eine mässige Asymmetrie beider Hälften und zwar insofern, als die rechte, dem Tumor anliegende Seite etwas gegen die linke, halbkreisförmige, abgeplattet ist. Ferner scheint der rechte Seitenstrang, sowie der rechte Kleinhirnseitenstrang stärker hell verfärbt, wie links. Hingegen lässt sich in der Intensität der Hinterstrangsdegeneration eine Differenz zwischen der rechten und linken Seite nicht finden. Die Degenerationsbezirke zeigen wiederum, mit Ausnahme der Kleinhirnseitenstrangbahnen, den Charakter der fleckweisen, nicht strangförmigen Degeneration. Die mikroskopische 
Betrachtung bestätigt den makroskopischen Befund bezüglich der Intensität der verschiedenen Degenerationsgebiete. - Die graue Substanz ist noch ziemlich scharf gezeichnet. Sie weist eine entschiedene Verminderung der Ganglienzellen auf.

Höhe des 3. Brustwirbels, mittlerer Theil $\left(D_{3 b}\right)$.

Dieser Schnitt bildet die gesteigerte Fortsetzung des vorigen. Er ist zunächst ebenso wie dieser unsymmetrisch. Nur ist hier die Asymmetrie ausgesprochener, so dass die dem Tumor entsprechende Hälfte geradezu zusammengedrückt aussieht, und zwar ist besonders die dorsale Partie abgeplattet. Ebenso unsymmetrisch ist auch die graue Substanz. Ihre Zeichnung ist durchaus verwaschen; die Contouren verschwimmen vollkommen mit der im Ganzen abnorm hell verfärbten Substanz. Immerhin sind die Umrisse vom linken Vorder- und Hinterhorn noch besser erhalten als von dem rechten.

In der weissen Substanz sind vor Allem die Hinterstränge einer starken, fleckweisen Degeneration verfallen. Fernerhin finden sich noch einige hellere Flecken in dem rechten Seitenstrange.

Höhe des 3. Brustwirbels, unterer Theil $\left(D_{3} c\right)$.

Dieser Querschnitt zeigt die Höhe der Degenerationserscheinungen an. Zunächst weist er eine starke Asymmetrie anf: Die rechte Seite ist gegen die linke an Volumen im Ganzen vermehrt. Ferner aber erscheint die ganze hintere Hälfte von beiden Seiten her plattgedrückt, so dass der Querschnitt im Ganzen nicht kreisrund, wie es in dieser Höhe der Fall sein sollte, sondern mehr eiförmig aussieht.

Stark asymmetrisch ist auch die grane Substanz, indem nehmlich das Vorderhorn der rechten Seite tiefer steht, als das der linken. Dic Zeichnung der grauen Substanz ist wenig scharf und besonders im linken Hinterhorn von hellweisslichen Einsprengungen unterbrochen.

Höhe des 4. Brustwirbels, oberer Theil $\left(D_{4 a}\right)$.

Dieser Querschnitt weist gegen den vorigen auffallend geringe Zeichen von Erkrankung auf. Er ist zunächst durchaus symmetrisch und im Ganzen viel dunkler als die vorhergehenden Querschnitte. Gröbere Degenerationen, seien es heerd-, seien es strangförmige, sind überhaupt nicht vorhanden. Nur die Seitenstränge heben sich in ihrer centralen Partie etwas von der Umgebung ab, sowie ferner zwei kommaförmige feine Streifen in den Hinterhörnern, die dicht unterhalb der Commissura posterior beginnend, parallel den Hinterhörnern fast bis zur Peripherie verlaufen, von jenen durch einen schmalen Streifen dunkleren Gewebes getrennt. 
Was die graue Substanz anlangt, so erscheint sie auch gegen das letzte Querschnittsbild unvergleichlich deutlicher, aber immer noch nicht ganz scharf.

Höhe des 4. Brustwirbels, unterer Theil $\left(D_{4 b}\right)$.

Dieses Segment bietet gegen das vorige kaum Neues. Sehr schön sind hier die beiden soeben erwähnten kommaförmigen Degenerationsstreifen zu sehen. Sie bilden hier eine Art von Hufeisen in der Weise, dass sie parallel der hinteren Commissur knieförmig umbiegen und sich in der Mittellinie treffen. Am deutlichsten sind sie in der Gegend des Hinterhornkniees, während sie nach der Peripherio des Querschnitts zu breiter, aber undeutlicher werden.

Die Seitenstränge sind nur noch mässig hell verfärbt, was, wie sich mikroskopisch leicht ergiebt, von einer nur noch geringen Degeneration von Axencylindern herrührt.

In den weiteren Querschnitten bis zum Ende des mir zur Verfügung stehenden Stückes nahm die kommaförmige Degeneration immer mehr ab und verschwand in der Höhe des 6. Brustwirbels. Die Degeneration in den Seitensträngen war, wenn auch schwach, bis zum Ende zu verfolgen.

Es handelt sich also in diesem Falle, in dem die Hauptcompression in der Höhe des 3. Brustwirbels lag, um eine aufsteigende Entartung der Kleinhirnseitenstrangbahnen und der Hinterstränge, beide bis zum oberen Ende des untersuchten Stückes, d. i. bis zum 7. Halswirbel deutlich verfolgbar. In den Hintersträngen waren besonders stark die Goll'schen Stränge (mit Ausnahme eines kleinen, ovalen, der hinteren Fissur anliegenden Bezirkes) weit weniger intensiv die Burdach'schen Stränge afficirt. In absteigender Richtung fanden wir typische Seitenstrangdegeneration bis zur Lendenwirbelsäule, sowie die "kommaförmige" Entartungsfigur Schultze's in den Hintersträngen bis zum 6. Brustwirbel.

\section{Fall III.}

Scholz, Jobann, Arbeiter, 47 Jabre alt.

Anamnese: Keine hereditäre Belastung. Patient selbst will früher stets gesund gewesen sein.

Seit einiger. Zeit leidet er angeblich an einem Nierenleiden, das er ambulatorisch in der Kgl. medicinischen Poliklinik behandeln liess. Nachdem er am Vormittage des 4 . Juni 1895 wiederum dieselbe aufgesucht und; 


\section{3}

trotz etwas geschwollener Füsse, beide Wege ohne besondere Beschwerden zu Fuss zurückgelegt batte, trat plötzlich in der Nacht vom 4. Mai eine enorme Verschlimmerung ein. Er bekam heftige Schmerzen in die Beine und konnte sie nicht mehr rühren, so dass er sich in's Allerheiligen Hospital transferiren liess.

Status praesens: 5. Juni.

Sehr anämisch aussehender Patient. Derselbe bietet das vollständige Bild der Rückenmarksunterbrechung.

Die unteren Extremitäten sind total paralytisch und völlig empfindungslos.

Die Sensibilitätsstörungen erstrecken sich in etwas abgeschwächtem Maasse bis unter den Rippenbogen nach oben. Oberbalb des Rippenbogens findet sich eine leicht Zyperüsthetische Zone. Die Anästhesie ist hinten zwischen 4, und 5. Brustwirbel begreazt.

Totale Retentio urinae et alvi. Sehnenreflexe an den Beinen gesteigert. Hautreflexe erloschen.

Der mit dem Katheter entnommene Urin enthält Eiweiss, mässig zahlreiche Cylinder, darunter granulirte, einige Nierenepithelien, einzelne Leukocyten, sehr spärlich rothe Blutkörperchen.

Die Beine sind leicht ödematös.

Verlauf: gestaltet sich so, dass schon am 3. Tage Cystitis mit hohem Fieber $(39,8)$ eintrat, sowie leichte decubitale Veränderungen am Kreuzbein. Dazu traten dann noch grosse Brandblasen an beiden Füssen. Im Laufe der nächsten Tage vergrösserte sich der Decubitus immer mehr. Appetit und Nahrungsaufnahme sehr gering. Doch konnte Patient auch Festes ohne Beschwerden schlucken.

18. Juni 1895. Exitus lethalis.

Sections-Protocoll. (Herr Dr. Welcker.) Grosse, sehr kräftige, männliche Leiche. Todtenstarre nicht gelöst. Untere Extremitäten ödematös. Fettpolster ziemlich beträchtlich. Bei Eröffnung der Brusthöhle ziehen sich beide Lungen wenig zurück. Das Herz liegt in ganzer Ausdehnung frei. Die linke Lunge ist binten ziemlich fest adhärent, ebenso die rechte. In der rechten Pleurahöhle ist eine geringe Menge leicht getrübter Flüssigkeit, im Herzbeutel finden sich etwa $100 \mathrm{ccm}$ klarer gelblicher Flüssigkeit. Das Herz ist etwas grösser als die Faust der Leiche. Beide Ventrikel sind schlaff. Der rechte Ventrikel ist leicht erweitert. Musculatur und Klappen sind leicht blutig infiltrirt. Deutlicbe Fettzeicbnung in der Musculatur des linken Ventrikels.

Linke Lunge: Oberlappen emphysematös. Unterlappen stellenweise verdichtet, stellenweise mit dünnem Schleime bedeckt.

Rechte Lunge: sebr voluminōs. Pleura im Oberlappen stellenweise baumförmig verdickt. Ober- und Unterlappen ziemlich schwer. Oberlappen stark ödematös, meist grauröthlich gefärbt. Unterlappen dunkelbraunroth, gleicbfalls stark ödematös. Auf Druck entleert sich aus den kleinen Bronchien gelbweisse, schleimig-eitrige Flüssigkeit. Die Pulmonalarterien sind ohne Inhalt. 
Beide Tonsillen stark geschwollen. Die Halsorgane werden in Zusammenhang mit dem oberen Theile der Brustwirbelsäule herausgenommen. Etwa $6 \mathrm{~cm}$ unterhalb des Schlundeingangs befindet sich ein erbsengrosses, in das Lumen des Oesophagus vorspringendes, mit höckriger Oberfläche versehenes Knötchen. Von diesem aus geht eine höckrige Infiltration des Oesophagus, die sich nach unten $3 \mathrm{~cm}$ lang fortsetzt, nach oben von dem isolirten Knötchen durch eine Art von Leiste gesondert ist. Weiter nach unten von der harten Infiltration der Oesophagus-Wand befindet sich eine $7 \mathrm{~cm}$ lange, hauptsächlich die hintere Wand einnehmende, mit weissen, stark zerfallenen, zottigen Massen bedeckto Anscbwellung. An der vorderen Wand finden sich zwei erbsengrosse, nicht zerfallene, isolirte Knötchen. Der Oesophagus ist an dieser Stelle ziemlich weich. Die Distanz ron den rom Carcinom freigelassenen Stellen der vorderen Wand beträgt $\mathbf{3} \mathrm{cm}$. Das untere Ende des Carcinoms hängt über der Ansatzstelle desselben an der Oesophagus-Wand hinunter. Unter dem grossen, flachen, zerfallenen Tumor befinden sich an der vorderen Wand noch zahlreiche, etwa linsengrosse und kleinere Knötchen, die $11 \mathrm{em}$ oberhalb der Cardia aufhören.

Die Halsdrüsen sind sehr stark vergrössert, hart anzufühlen und auf dem Durcbschnitt von krebsigen Massen durchsetzt.

An der Wirbelsäule ist das Carcinom in der Gegend des 3. Brustwirbels sebr fest adbärent. Auf der durchsägten Wirbelsäule zeigt sich der 3. Wirbelkörper völlig cariös mit krebsigen Massen durchsetzt. Im Körper des 2. Brustwirbels eine nicht scharf begrenzte, krebsige Infiltration. Der 4. Brustwirbel ist besonders in den hinteren Partien diffus krebsig infiltrirt. Er ist nur $10 \mathrm{~mm}$ hoch, während der unter ihm liegende $18 \mathrm{~mm}$ misst. Im Wirbelkanal findet sich ein von dem cariösen Brustwirbel nach beiden Seiten hin sich erstreckendes, flaches, höckriges, $5 \mathrm{~cm}$ langes Polster.

Die Dura ist, soweit nachgewiesen, nicht mitafficirt.

Bauch-Situs: Das ziemlich fettreiche Netz bedeckt die vorliegenden, stark mit Gasen gefüllten Schlingen des Coecum, des Colon descendens und des $\mathrm{S}$ romanum fast völlig.

Der Magen ist dilatirt, stark mit Gasen gefüllt.

Zwerchfellstand rechts 5. Rippe, links 5. Intercostalraum.

Im Munde weissgrüne, bröcklige, dünnbreiige Massen.

Milz: um's Doppelte vergrössert, weich, zerfliesslich.

Leber gross, $27 \mathrm{~cm}$ lang, $21 \mathrm{~cm}$ breit. Die Kapsel zeigt stellenweise eine leichte Trübung, die auf fibrinöser Belegung berubt. Die Substanz ist ziemlich fest. Läppchenzeichnung wenig deutlich, bell röthlich-braun.

Die Gallenblase ist mit gelber Galle gefüllt. Ductus choledochus durchgängig.

Rechte Niere sehr gross und fettreich. Kapsel nicht glatt abziehbar, bleibt an der Oberfläche stellenweise haften. Die Substanz ist ziemlich weich, gedunsen. Die ganze Niere hat eine gleiche, schmutzig-gelbbraune Farbe mit punktförmigen, hellgelblich-braunen Einsprenkelungen. Die Markkegel heben sich nur hier und da als bräunliche, gelbgestreifte Pyramiden ab. 


\section{5}

Die linke Niere ist ebenso gross wie 'die rechte; ebenfalls weich, auf dem Durchschschnitt sebr bunt, braun und rötblich-hellgelblich gefleckt.

Nebennieren ohne Besonderheiten.

Diagnose: Carcinoma oesophagi permagnum. Nephritis parenchymatosa chronica. Myodegeneratio cordis adiposa. Hyperplasia lienis acuta permagna. Metastases carcinomatosae in glandulis lymphaticis colli. Metastasescarcinomatosae in corporibus vertebrarum dorsalium II.-IV. Caries fere totalis corporis vertebrae dorsalis III. Compressio levis medullae spinalis dorsalis. -

Hypertropbia tonsillaris.

Empbysema palmoun. Bronchopneumonia lobi inf. sin.

Broncbitis diffusa. Oedema pulmonum.

Pleuritis adhaesiva bilateralis.

Das Rückenmark dieses Falles, das zunächst wie die anderen in Müller'scher Flüssigkeit einige Monate conservirt worden war, wurde nach der Marchi'schen Osmiurnsäure-Methode weiter behandelt. Leider stand mir nicht das ganze Centralorgan, sondern uur ein Stück von $16 \mathrm{~cm}$ Länge zur Verfügung, welches das Dorsalmark vom obersten bis zum siebenten Brustwirbel umfasste. Dasselbe wurde in Segmente von $0,5 \mathrm{~cm}$ Höhe zerlegt, die einzelnen Stückchen osmirt, in Celloidin eingebettet und geschnitten.

Jie Methode bewährte sich ganz ausserordentlich. Denn traten schon makroskopisch die degenerirten Partien in toto mit grosser Deutlicbkeit hervor, so waren mikroskopisch selbst ganz vereinzelte erkrankte Fasern innerhalb sonst gesunden Gewebes ohne jede Mühe zu sehen. Besonders schöne Bilder ergaben diese osmirten Schnitte, wenn sie noch mit Saffranin sorgfältig nachgefärbt wurden. Es sei mir gestattet, zunächst wiederum nur die Topographie der Degenerationen in den einzelnen Segmenten zu besprechen und die histologischen Details erst später folgen zu lassen.

\section{Höhe des 1. Brustwirbels (III, $D_{1}$ ).}

Schon an dem nur von Müller'scher Flüssigkeit durchtränkten, noch nicht osmirten Stücke zeigt das Querschnittsbild eine auffallend helle, flaschenförmige Degenerationszone, welche die Goll'schen Stränge betrifft. Dieselbe nimmt nach dem Centralkanal hin an Intensität zu, während sie peripheriewärts bedeutend schwächer wird und schliess- 


\section{6}

lich fast $\mathrm{zu}$ verschwinden scheint. Ventral, d. h. also an der hinteren Commissur, breitet sie sich hakenförmig nach beiden Seiten hin längs derselben aus. Nächstdem sehen auch die Burdach'schen Stränge heller als der übrige gesunde Querschnitt aus, obschon lange nicht so bell, wie die Goll'schen Stränge. Nur eine kleine, spitzdreieckige Partie hart am Fusse des Hinterhorns hebt sich durch besonders helle Verfärbung hervor und scheint sogar noch stärker afficirt als die Goll'schen Stränge. Schliesslich findet sich noch ein etwas hellerer Streifen zu beiden Seiten des Querschnitts zwischen Vorder- und Hinterhorn, also in der Gegend der Kleinhirnseitenstrangbahnen. Nicht unerwähnt möchte ich lassen, dass ein schmaler Streifen zwischen dem Burdach'schen und Goll'schen Strange frei bleibt. Derselbe zieht sich von der Höhe etwas oberhalb der Substantia gelatinosa Rolandi sich verjüngend bis etwa zur Peripherie und ist auch bei der mikroskopischen Untersuchung viel geringer degenerirt als die übrigen Hinterstränge.

Ein den Müller-Präparaten ganz entsprechendes Bild geben die Querschnitte der osmirten Stücke, deren mikroskopische Betrachtung den makroskopisch erhobenen Befund bestätigt nnd erweitert. Die stark geschwärzten Degenerationspartien enthalten zahlreiche gequollene oder in Zerfall begriffene Axencylinder, gekräuselte und verdünnte Markscheiden von undeutlicher oder gänzlich verwischter concentrischer Schichtung, erweiterte Lymphgefässe, sowie die anderen der ${ }_{7} \mathrm{Com}$ pressionsmyelitis" eigenthümlichen Veränderungen, die weiter unten eingehender besprochen werden sollen.

Bemerkenswerth ist, dass mikroskopisch die Degenerationszone der Kleinhirnseitenstrangbahn nach innen in der Gegend der Vorderhörner deutlich etwas vorspringt, wie schon Gowers, Schultze u. A. (s. unten) beschrieben haben. -

Am schwersten betroffen ist die schon oben besonders hervorgehobene Zone am peripherischen Ende der Hinterhörner. Dieselbe zeigt fast nur schwer entartete Nervenfasern. Dieselben gehören zum Theil den hinteren Wurzeln an und strahlen in den dicht unterhalb der Substantia gelatinosa liegenden Bezirk der Burdach'schen Stränge ein.

Ausser diesen grossen, geschlossenen Strangdegenerationen finden sich noch hie und da auch in sonst unversehrtem Gewebe vereinzelte geschwärzte Axencylinder.

Die graue Substanz ist etwas blass (im Müller-Präparat), jedoch durchaus deutlich erkennbar. Die Zahl der Ganglienzellen scheint etwas vermindert, im Filzwerk der grauen Substanz finden sich degenerirte Fasern in mässiger Menge. 
Höhe des 2. Brustwirbels (oberer Theil) (Das).

Dieser Querschnitt bietet gegen den vorigen kaum Neues. Nur sind auch die Burdach'schen Stränge stärker an der Degeneration betheiligt.

Höhe des 2. Brustwirbels (unterer Theil) $\left(D_{2 b}\right)$.

Der Querschnitt erscheint am Müller-Präparat im Ganzen etwas heller, am Osmium-Präparat im Ganzen etwas dunkler als die vorhergehenden, was, - wie mikroskopisch leicht ersichtlich ist, - davon herrührt, dass sich degenerirte Axencylinder diffuse zerstreut in grösserer Anzahl vorfinden als in dem vorhergehenden Querschnitte. Von besonders intensiver, heller bezw. dunkler Färbung erweisen sich die Hinterstränge und zwar ist in diesem Segment, wenigstens im ventralen Theile kaum noch eine Nuancenverschiedenheit zwischen den Goll'schen und Burdach'schen Strängen constatirbar. Dorsalwärts allerdings wird nicht sowohl die Degeneration der Goll'schen und Burdach'schen Stränge, als auch die der letzteren im Vergleich zu den ersteren schwächer. Von der oben erwähnten freieren, kommaförmigen, sowje der schwerer geschädigten dreieckigen Partie neben den Hinterhörnern ist in diesem Segment nichts wahrzunehmen.

Das Auffallendste jedoch an diesem Querschnittsbilde sind zwei rundliche Degenerationsfelder in der weissen Substanz zwischen Vorderund Hinterhorn dicht am centralen Ende des Hinterhorns. Dieselben sind ganz symmetrisch gelagert und etwa gleich gross. Ihre Gestalt ist oval. Die Längsaxe steht frontal und beträgt etwa die Hälfte der Breite der weissen Substanz, die darauf senkrechte Axe etwa nur $\frac{2}{3}$ derselben. Bei der mikroskopischen Untersuchung dieser eigenartigen Degenerationsfelder zeigt es sich, dass sie nicht ganz gleichartig sind, insofern, als das eine entschieden einem vorgeschritteneren Degenerationsstadium entspricht als das andere. Letzteres bietet in Folge dessen auch übersichtlichere Verhältnisse, weshalb wir diese zunächst unserer Besschreibung zu Grunde legen wollen: Es handelt sich bei demselben um zwei, deutlich von einander gesonderte Zonen, eine peripherische und eine concentrische. Die erstere ist weitaus stärker afficirt als die letztere und besteht im Wesentlichen aus degenerirten Nervenfasern. Dieselben sind zum grössten Theil im Längsschnitt getroffen, strahlen zunächst, wie es scheint, am dorsalen Theile neben der grauen Substanz ein, wenden sich dann lateral und biegen dann wieder medialwärts um, laufen also scheinbar concentrisch um die Innenzone herum. Sie sind alle geschwärzt und reichlich mit varicösen Ausbuchtungen von mässiger, oft ansehnlicher Grösse versehen. Die Kernzone ist weit heller und weist dem entsprechend nur geringe De- 


\section{8}

generationen auf. Sie besteht hauptsächlich aus quergeschnittenen Nervenfasern.

Wie schon erwähnt, ist diese Anordnung auf der anderen Seite nicht so deutlich, aber immerhin noch constatirbar. Die Randzone ist stark afficirt; sie zeigt vielfach grossmaschige Defecte, hingegen weit weniger degenerirte Axencylinder als die andere Seite. Nicht unerwähnt möchte ich lassen, dass in der Umgebung dieser Felder, besonders nach der Gegend der Pyramidenseitenstrangbahnen bin, noch grössere Ansammlungen von degenerirten Axencylindern sich vorfinden und zwar mehr rechts als links. Jedoch tritt nirgends wieder eine den beiden soeben beschriebenen ähnliche Gruppe auf. Wie erwähnt, handelt es sich auf der linken Seite um eine nur mässige Degeneration von Axencylindern, auf der anderen hingegen um eine entschieden stärkere mit zahlreichen geschwärzten oder schollig zerfallenen, ungeschwärzten Axencylindern. Stellenweise sind dieselben sogar bereits verschwunden und haben grosse Maschen zurückgelassen, in denen zum Theil noch die grau gefärbten, gekräuselten, stark verdünnten Markscheiden sichtbar sind.

Höhe des 3. Brustwirbels (oberer Theil) ( $D_{3 a}$ ).

Bei der makroskopischen Betrachtung dieses Querschnitts fällt eine starke Asymmetrie beider Bildhälften auf. Die ganze rechte Hälfte ist weniger rund wie die linke, mehr lateralwärts verbreitert, dagegen von vorn nach hinten abgeplattet. Dem entsprechend ist auch das ganze rechte Hinterhorn lateralwärts verschoben. Ferner erscheint das ganze Querschnittsbild im Müller-Präparat heller, bezw. im Osmiumpräparat dunkler, wie in den vorhergehenden Abschnitten. In der That besteht eine starke diffuse Degeneration über den ganzen Querschnitt hin. Besonders stark ergriffen sind die Hinterstränge. Sie bestehen fast nur aus degenerirten Axencylindern. Jedoch finden sich auch in den Seiten- und Vordersträngen zahlreiche gequollene und geschwärzte Axencylinder und weite, bereits axencylinderlose Maschen.

\section{Höhe des 3. Brustwirbels (unterer Theil) ( $\left.D_{3 b}\right)$.}

Das Querschnittsbild dieses Segments, das sich schon bei der Section durch seine besonders weiche Consistenz als am meisten geschädigt erwies, zeigt sehr schwere Veränderungen. Zunächst ist es, wie das vorige, unsymmetrisch, und zwar handelt es sich auch hier um eine Vergrösserung der rechten Hälfte zu Ungunsten der linken. Sodann ist das Querschnittsbild gänzlich verwischt; von der grauen Substanz sind die Vorderhörner nur sehr undeatlich, die Hinterhörner wenigstens noch einigermaassen erkennbar. 
Mikroskopisch zeigt sich, dass die ersteren eine sehr starke Reduction erfahren haben. Sie sind ganz klein und weisen nur spärliche Ganglienzellen auf, die klein und nach verschiedenen Richtungen hin degenerirt aussehen, z. B. keinen Kern, oder wenn dieser vorhanden ist, keinen Nucleolus haben.

Der Centralkanal ist kaum angedeutet, mit zelligen Elementen angefüllt, die vordere und hintere Commissur nicht zu unterscheiden.

In der weissen Substanz bestehen die schwersten Veränderungen in den Pyramidenseitenstrang- und Pyramidenvorderstrangbahnen. Dieselben bestehen zum grössten Theile aus grossmaschigem Gewebe, welches kaum noch Axencylinder enthält. Dagegen finden sich zahlreiche, mit geschwärztem, theils tropfenförmigem, theils mehr grobkörnigem Fett beladene Körnchenzellen und erweiterte, stark gefüllte Gefässe, allein nirgends Leukocyteninfiltration.

Höbe des 4. Brustwirbels (oberer Theil) $\left(D_{4 a}\right)$.

Das Querschnittsbild ist auffallend gut erhalten. Es ist durchaus symmetrisch; deutlich und zeigt im Wesentlichen strangförmige Degenerationen, und zwar finden sich dieselben erstens in den Seitensträngen, sodann als feine Streifen in den Vordersträngen dicht neben der vorderen Fissur und in den Hintersträngen dicht neben den Hinterhörnern. Die letzteren sind besonders in ihrem ventralen Theil deutlich zu sehen.

Geringe Randdegenerationen, besonders mit Beginn der Veränderungen in den Markscheiden, wurden, da sie höchst wahrscheinlich grösstentheils postmortal sind, nicht berücksichtigt. Gelang es mir doch mehrmals, in dem Gewebe and den Lymphgefässen der Pia and der subpialen Partien Bakteriencolonien nachzuweisen.

Höhe des 4. Brustwirbels (unterer Theil) $\left(D_{4 b}\right)$.

Es zeigen sich hier im Wesentlichen dieselben Veränderungen, wie im letzten Querschnitte: Degenerationen der Pyramidenvorder- und -seitenstränge, sowie eines schmalen, kommaförmigen Bezirkes in den Burdach'schen Strängen.

Diese Topographie der Degenerationen besteht im Allgemeinen in den folgenden Segmenten fort; nur nimmt die Intensität der Entartung von Segment zu Segment etwas ab. Hervorheben möchte ich noch, dass die kommaförmige Degenerationszone der Hinterstränge noch bis zum Ende, d. i. bis zum 7. Brustwirbel incl., makroskopisch, wenn auch schwach, so doch deutlich sichtbar blieb.

Werfen wir noch einen Rückblick auf diese letzte Serie, so bemerken wir eine interessante Uebereinstimmung mit dem Falle II, die wohl am leichtesten dadurch ihre Erklärung findet, 
dass in beiden Fällen die stärkste Schädigung an derselben Stelle, dem 3. Brustwirbel, statt hatte. Wie in Fall II haben wir denn auch hier in aufsteigender Richtung Entartung der Kleinhirnseiten- und Hinterstränge, in absteigender Richtung der Seitenstränge und des Schultze'schen Kommas, und zwar bleibt auch letzteres noch bis zum 7. Brustwirbel verfolgbar. Zu diesen, im Wesentlichen mit Fall II übereinstimmenden Befunden an Strangdegenerationen gesellt sich als neve Beobachtung die absteigende Vorderstrangdegeneration (bis num 4. Brustwirbel einschl.) hinzu.

Fassen wir nun die Ergebnisse vorstehender Beobachtungen zusammen, so ergiebt sich zunächst für

\section{die Topographie der Degenerationen}

Folgendes: Wie schon aus der Beschreibung der einzelnen Segmente ersichtlich, hat man es bei der sog. Compressions-Myelitis mit 2 Formen vou Degenerationen zu thun, nehmlich 1) der heerdförmigen, 2) der strangförmigen.

Die heerdförmige Degeneration kommt fast ausschliesslich an der Compressionsstelle und ihrer nächsten Umgebung zur Beobachtung. Nur sehr selten findet man in weiterer Entfernung von der Compressionsstelle ein inselförmiges Degenerationsgebiet, dessen intravitale Präexistenz jedenfalls stets zweifelhaft erscheinen muss. Die heerdförmige Degeneration besteht in einzelnen, oft sehr zahlreichen Degenerationsheerden, die unregelmässig entweder über den ganzen Querschnitt oder nur auf einzelne Theile desselben regellos verstreut sind. Sowohl ihre. horizontale wie verticale Ausdehnung, als auch die Schwere der Veränderungen innerhalb der einzelnen Heerde ist durchaus verschieden. Immerhin lässt sich sagen, dass (z. B. im Falle I Neugebauer) an der dem Tumor entsprechenden Seite die Heerde sowohl am zahlreichsten als auch am grössten sind, sowie auch die schwersten Verheerungen aufweisen. Bemerkenswerth ist ferner, dass, wie man ebenfalls am Fall I deutlich nachweisen kann, die Schädigungen des Gewebes direct unterhalb der Pia, also direct unter dem Drucke, nicht so gross sind wie mehr im Binnenraume des Rückenmarkssegmentes. Hier aber erscheinen besonders die Seitenstränge und nach ihnen 
die Hinterstränge, weit weniger die vorderen Partien erfasst. Worauf diese Verschiedenheit beruht, ist vor der Hand nicht zu entscheiden. Vielleicht handelt es sich darum, dass die peripherischen Nervenelemente einen gewissen Schutz durch die spongiöse Schicht geniessen, die das Rückenmark rings umschliesst, vielleicht sind sie an und für sich resistenter, da ja doch nachgewiesenermaassen die Widerstandsfähigkeit der Axencylinder in den einzelnen Partien des Rückenmarks eine verschiedene ist. Ferner käme zu dieser grösseren Laedibilität noch die Thatsache hinzu, dass die von der Peripherie aus einstrahlenden, die Seitenstränge versorgenden Arteriae spinales laterales als Endarterien seitlich von der grauen Substanz enden, dass demnach hier im Falle einer Gefässverlegung am ehesten Ischämie eintreten kann, die zusammen mit der für die Nervenelemente so gefährlichen Stauungslymphe die allerschwersten Zerstörungen hervorrufen kann. Ferner ist es auch möglich, dass von der bereits abgestorbenen Nervensubstanz oder von dem comprimirenden, häufig zu Zerfall neigenden Tumor toxische Einflüsse ausgehen, die erst dann ordentlich zur Wirkung kommen, wenn eine Gewebspartie durch verminderte arterielle Versorgung mangelhaft ernährt und dadurch geschwächt ist.

Die strangförmigen Degenerationen bestehen in den im Wesentlichen seit den grundlegenden Arbeiten Türck's und seiner Nachfolger bekannten Entartungen längs eines Fasersystems, und zwar finden wir oberhalb der Compressionsstelle Entartung der Hinterstränge und Kleinhirnseitenstrangbahnen, unterhalb der Compression der Seitenstränge, der Vorderstränge, sowie eines kleinen, erst neverdings bekannt gewordenen Bezirkes in den Hintersträngen.

Die aufsteigende Degeneration in den Hintersträngen umfasst dicht oberhalb der Compression den ganzen oder fast den ganzen Bezirk zwischen den beiden Hinterhörnern, nimmt allmählich zu Gunsten der Burdach'schen Stränge mehr und mehr ab, so dass schliesslich diese ganz frei werden und nur noch die Goll'schen Stränge degenerirt sind. Diese Gesetzmässigkeit der Hinterstrangsdegeneration beruht darauf, dass die Fasern der Grundbündel im Wesentlichen aus den hinteren Warzeln stammen, und mit jedem neuen Segment immer neue einstrahlen, so dass wir, je höher wir hinaufgehen, desto mehr unversehrte Fasern finden. 
Die Degeneration des kleinen dreieckigen Bezirkes medial von den Hinterhörnern, welche im Falle I (s. Fig. I, $\mathrm{C}_{1}$ ) besonders gut ausgeprägt war, ist wohl aus der Degeneration von Fasern der hinteren Wurzeln zu erklären.

Schwerer gestaltet sich die Frage nach der Bedeutung des ovalen, ausgesparten Feldes zwischen den entarteten Goll'schen Strängen zu beiden Seiten der Fissura posterior, welches im Falle II deutlich zu constatiren war. Dieses Feld, das ich in solcher Höhe (VII. Halswirbel) bisher noch nirgends erwähnt gefunden habe, entspricht topographisch Flechsig's Medianzone. Sein Freibleiben bei, im Uebrigen starker, aufsteigender Degeneration wird auch von Schultze ${ }^{2}$ ) und Gowers ${ }^{2}$ ) beschrieben und abgebildet. Absteigend wurde es von Daxenberger ${ }^{3}$ ), sowie von Gombault und Philippe ${ }^{4}$ ) degenerirt gefunden, während es Schaffer ${ }^{5}$ ) trotz stark entarteter Hinterstränge in dieser Richtung frei bleiben sah. Eine Deutung dieses Bezirkes ist vor der Hand kaum möglich. Philippe und Gombault meinten, dass die absteigende Degeneration der Hinterstränge im oberen Theile des Rückenmarks die "sog. „kommaförmige" Zone Schultze's, im unteren Theile diese mediane Partie einnehme. Indessen kann ich dies nach meinen Präparaten nicht bestätigen, wenigstens für die absteigende Richtung nicht, während allerdings aufsteigend ein schmaler Streifen (zwischen dem flügelförmigen Anhange und der Hauptdegeneration) freier blieb, welcher nun aber nicht recht an der Stelle des Kommas lag, sondern etwas mehr medianwärts. Wie dem auch sei,

1) Schultze, Friedrich, Beitrag zur Lehre von der secundären Degeneration im Rückenmark nebst Bemerkungen über die Anatomie der Tabes. Arehiv für Psych. Bd. XIV. S. 379.

2) Gowers, Handbuch der Nervenkrankbeiten. Uebersetzt von Dr. Carl Grube. Bd. I. 1892. S. $190 \mathrm{ff}$.

3) Daxenberger, Ueber einen Fall von chronischer Compression des Halsmarks mit besonderer Berücksichtigung der secundären absteigenden Degeneration. Deutsche Zeitschr. für Nervenheilk. Bd. IV. S. 136.

4) Gombault und Philippe, ref. nach Leyden und Goldscheider, Die Erkrankungen des Rückenmarks und der Medulla oblongata. Bd. I. S. 86.1895.

5) Schaffer, K., Beitrag zur Histologie der secundären Degeneration. Archiv für mikroskop. Anat, Bd.43, 2. 1893 , 
jedenfalls handelt es sich um ein gesondertes Fasersystem, das ja von Flechsig schon entwickelungsgeschichtlich von dem übrigen, viel später entstehenden Hinterstrange abgetrennt wurde.

Ausser den Hintersträngen finden wir in aufsteigender Richtung auch die Kleinhirnseitenstrangbahnen degenerirt. Bei der peripherischen Lage dieser Bahnen muss man, wie bei allen Randdegenerationen, sehr vorsichtig in der Beurtheilung auftretender Veränderungen sein, und die vielfachen Discussionen gerade über diese Degenerationsgebiete beweisen wohl am besten die Schwierigkeit und Unsicherheit ihrer Darstellung. Immerhin können wir für alle 3 Fälle sagen, dass oberhalb der Compression die seitliche Randpartie zwischen Vorder- und Hinterhorn deutlich degenerirt war. Sie reichte im Allgemeinen im oberen Hals- und dem Brusttheile bis fast an die Hinterhörnor, im unteren Halstheile nur etwa bis zur Mitte des Querschnitts. Im Falle III konnte ich in der Höhe des 1 . Brustwirbels an den Kleinhirnseitensträngen einen nach den Vorderhörnern zu spitz vorspringenden Winkel beobachten. Derselbe stellt ein Degenerationsgebiet dar, das Gowers $\left.{ }^{1}\right)^{2}$ ) zum ersten Male unter dem Namen "Tractus antero-lateralis ascendens" beschrieb und dabei die Vermuthung aussprach, dass der Strang aus Fasern bestehen könnte, welche ihren Ursprung in der hinteren Commissur hätten. Nebenbei möchte ich noch erwähnen, dass ich, wie schon Strümpell ${ }^{3}$ ) beschrieb, gleichfalls auch in absteigender Richtung vereinzelte degenerirte Nervenfasern in den Kleinhirnseitenstrangbahnen (in Osmiumpräparaten) gefunden habe. Indessen halte ich ihre intravitale Präexistenz nicht für zweifellos.

In absteigender Richtung finden wir zunächst die Seitenstränge afficirt und zwar besonders die Pyramidenbahnen. Dieselben haben je nach der Höhe des Segments peripheriewärts eine etwas verschiedene Ausdehnung, indem sie in der Höhe des 3. Halswirbels ( - höher hinauf war in meinen 3 Fällen die Untersuchung unmöglich und hat nach Gowers auch bisher zu

1) Gowers, Diagnosis of diseases of the spinal cord. 1. Edit. 1879.

2) Gowers, Handbuch der Nerventrankheiten. Bd. I. S. 195.

3) Strümpell, eit. nach Leyden und Goldscbeider, Die Erkrankungen des Rückenmarks und der Medulla oblongata. Bd.I. Allgemeiner Theil. 5. 86. 1895. 
keinem sicheren Resultate geführt -) bis an die Peripherie heranreichen, dann jedoch von derselben durch die Kleinhirnseitenstrangbahnen abgedrängt werden und erst wieder in der Höhe des 5. bis 6. Brustwirbels die frühere Ausdehnung gewinnen.

Ferner sind die Pyramidenvorderstrangbahnen degenerirt. Diese Degeneration ist besonders gut an den Osmium-Präparaten zu sehen, während sie an den anders behandelten Schnitten weit weniger deutlich hervortritt. Dieselben waren an Fall III bis etwa zum 5. Brustwirbel, an Fall I nur bis zum 4. Halswirbel zu verfolgen, an Fall II, bei dem die Compression in der Höhe des 3. Brustwirbels lag, gar nicht constatirbar, was mit der vielfach beschriebenen Inconstanz dieser Bahnen sohr wohl im Einklange steht.

Schliesslich konnte ich an Fall II und III die erst neuerdings genauer bekannt gewordene „kommaförmige absteigende Degeneration" in den Hintersträngen beobachten. Dieselbe trat bei beiden Fällen dicht hinter der Compression in der Höhe des 4. Brustwirbels auf und war bis zum 6. Brustwirbel in Fall II, bis zum 7. in Fall III zu verfolgen. Ihre Localisation war typisch an der Grenze zwischen Burdach'schem und Goll'schem Strange, ein wenig mehr dem ersteren anliegend. Diese eigenartige Strangdegeneration wurde zuerst ausführlicher von Schultze ${ }^{1}$ ) beschrieben, nachdem sie schon vorber von West$\mathrm{phal}^{2}$ ), Kahler und $\mathrm{Pick}^{3}$ ), Vulpian ${ }^{4}$ ) und Strümpell ${ }^{5}$ ) beobachtet worden war. Ihre Deutung war zunächst recht schwierig. Vulpian hielt sie überhaupt nicht für normal, sondern rechnete sie zu den "Abnormitäten der bei Thieren

l) Schultze, Friedrich, Beitrag zur Lehre von der secundären Degeneration im Rückenmark nebst Bemerkungen über die Anatomie der Tabes. Archiv für Psych. Bd. XIV. 1883. S. 379.

2) C. Westphal, Ueber eine Combination von secundärer, durch Compression bedingter Degeneration des Rückenmarks mit multiplen Degenerationsheerden. Archiv für Psych. Bd.X. S. 788. 1879.

3) Kahler und Pick, Beiträge zur Symptomatologie und pathologischen Anatomie der Rückenmarkscompression. Archiv für Psych. Bd. X. S. 186.1879.

4) Vulpian, cit. nach Kahler und Pick, ebendaselbst.

5) Strümpell, Myelitis dorsalis, verlaufend mit den Symptomen der spastischen Spinalparalyse. Archiv für Psych, Bd.X. 1879. 
beobachteten secundären Degeneration", während Kahler und Pick sie den übrigen Fasersystemen gleichwerthig erachteten, ohne den Ursprung dieses Systems genauer präcisiren za können, und Schultze selbst sagt hierüber Folgendes: "Ich sehe nur den Ausweg, dass es sich bei den abwärts entarteten Fasern um nach unten umbiegende Fasern der hinteren Wurzeln handeln könnte, wie solche, nach Stilling, in den Keilsträngen vorkommen." Er hielt sie also für kurze Bahnen. Dieser Ansicht trat $\mathrm{T}_{0 o t h}{ }^{1}$ ) entgegen, nicht nur deshalb, weil nach Durchschneidung der hinteren Wurzeln diese Degeneration ausbliebe, sondern auch, weil er das Komma sehr tief herunter verfolgen konnte, und es ihm unwahrscheinlich vorkam, dass die absteigenden Aeste der hinteren Wurzeln so tief herunterreichen könnten. Er wendet sich vielmehr der Anschauung zu, dass es sich um Commissurenfasern handele, und Marie ${ }^{2}$ ) erweiterte diese Ansicht dahin, dass die Fasern aus der grauen Substanz entsprängen, und die Degeneration von der Betheiligung der grauen Substanz abhinge.

Auch durch die neuesten Arbeiten $\left.\left.{ }^{3}\right)^{4}\right)^{5}$ ) ist über den Ursprung der Fasern keine grössere Klarheit gebracht worden. Immerhin ist nunmehr als gesichert zu betrachten, dass es sich um einen langen, das ganze Dorsalmark durchlaufenden Faserstrang handelt. Nicht unerwähnt möchte ich die interessante Hypothese lassen, die $\mathrm{Mann}^{5}$ ) über die Function dieser Bahn anstellt: "Wenn man bedenkt, dass sie durch das ganze Dorsalmark verläuft, in demselben durch Abgabe von Fasern allmählich immer schmäler wird und in Anbetracht der Degenerationsrichtung doch jedenfalls eine centrifugale Function hat, so könnte man auf den Gedanken kommen, dass sie der Innervation der Intercostales dient, was in meinen und auch dem Krauss'schen ${ }^{4}$ ) Falle mit dem klinischen Befunde in Einklang stehen würde".

1) Tooth, cit. nach Leyden und Goldscheider, Die Erkrankungen des Rückenmarks. Bd. I. S. 86.

2) Marie, ebendaselbst.

3) Hoche, Archiv für Psych. Bd. 28. 2. Heft.

4) Krauss, Zeitschr. für klin. Med. 1891. XVIII. Fall 2.

5) Mann, Klinische und anatomische Beiträge zur Lehre von der spinalen Hemiplegie. Zeitschr, für Nervenheilk. Bd. X. 1896. 
Leider finden sich in meinen eigenen Fällen keinerlei Notizen über die Function der Intercostalmusculatur.

Die Betheiligung der grauen Substanz an den beschriebenen Degenerationsprozessen lässt sich mit den jetzt gebräuchlichen Methoden nur schwer constatiren, bezw. es lassen sich Veränderungen nicht zweifellos als Folgen der Erkrankung erweisen. Nur an den Compressionsstellen selbst sind die Veränderungen so augenfällige, dass man über ihre Abhängigkeit von der Erkrankung schlechterdings nicht im $Z_{\text {weifel sein kann. So sehen }}$ wir an dieser Stelle in allen unseren Fällen schon makroskopisch die graue Substanz ganz grob in ihrer Form oder in der Schärfe der Zeichnung beeinträchtigt. Was hierbei

die histologischen Veränderungen der grauen Substanz anlangt, so äussern sie sich in einer Reduction des das Rückenmarksgrau bildenden Flechtwerks, sowie in einer Verminderung und Veränderung der Ganglienzellen. Dieselben sind zum Theil gering geschwollen, jedoch noch gut färbbar, zum Theil schon etwas getrübt und von geringerer Färbbarkeit, sowie von einer feinkörnigen, die Contouren des Kernes manchmal etwas verdeckenden Masse erfüllt. Häufig finden sich auch Zellen, bei denen die Protoplasmafortsätze undeutlich oder ganz verschwunden sind; manchmal - ein noch weiteres Stadium der Degeneration, - ist auch der Axencylinder geschwollen, wie abgeknickt oder gar nicht mehr sichtbar. In noch vorgeschrittenerer Veränderung befinden sich Zellen, deren Kern undeutlich oder gar unsichtbar ist. In solchen Fällen ist dann manchmal noch der Nucleolus deutlich zu sehen, der sich oft auffallend lange in der sonst schon stark veränderten Zelle erhält. - Andererseits kann auch der Kern erhalten sein, dabei aber die Zelle im Ganzen geschrumpft erscheinen. Derartige degenerirte Zellen enthalten oft sehr viel graubräunliches, bald grob-, bald mehr feinkörniges, Pigment, das viele Autoren veranlasste, unter den verschiedenen Stadien der Ganglienzellentartung auch eines der Pigmentdegeneration aufzustellen. Jedoch muss man bei der Beurtheilung dieser Bilder äusserst vorsichtig sein. Wie u. a. auch Schulz ${ }^{1}$ )

1) Schulz, R., Ueber arteficielle, cadaveröse und pathologische Veränderungen des Rückenmarks. Neurolog. Centralbl. 1882. No. 23, 24. 
schreibt, enthalten die Ganglienzellen älterer Leute, auch wenn sie nie Krankheitserscheinungen von Seiten des Centralnervensystems gehabt haben, häufig reichliche Mengen von Pigment, und es ist wahrscheinlich, dass dies manchmal auch schon bei jüngeren Personen symptomlos auftritt, während geringe Pigmentirung ja sogar zur Charakteristik der Ganglienzelle gehört, und manche Autoren dieselbe als das Produkt normaler Zellthätigkeit ansehen. Dass wir dann weiterhin Stadien antreffen, in denen die pigmentirte kernhaltige Zelle kernlos werden und schliesslich sogar zu einem unorganisirten Häufchen von blossen Pigmentkörnern zerfallen kann, spricht meines Erachtens nicht gegen die Präexistenz des Pigments in gesunden Tagen.

Bis zu derselben tiefen Stufe von Entartung kann auch die geschwollene Ganglienzelle herabsinken: In dieser kann nach dem Kerne auch der Nucleolus verschwinden, und dann die ganze Zelle körnig zerfallen, so dass an ihrer Stelle nur noch etwas schollig-körniges Material übrig bleibt.

$O b$ bei diesen degenerativen Vorgängen eine Bildung von Fett oder fettähnlichen Körpern stattfindet, ist bisher nicht sicher bekannt geworden. Nach meinen Präparaten nun kann ich versichern, dass ich trotz überaus langen Suchens auch nicht eine einzige Ganglienzelle gefunden habe, in der sich Bestandtheile des Zellleibes in der für Fett charakteristischen Weise gefärbt hätten. Allerdings sah ich öfters Ganglienzellen, in denen das etwas grobkörnige, schwärzliche Pigment vielleicht den Gedanken an eine Verfettung hätte erwecken können. Jedoch musste die Gleichförmigkeit, die enge Aneinanderlagernng, sowie schliesslich auch die nicht reinschwarze Farbe dieser Elemente diesen Verdacht sogleich widerlegen, und ich möchte mir daher den Schluss erlauben, dass bei den vorliegenden Prozessen Verfettungsvorgänge in den Ganglienzellen jedenfalls nicht statthaben.

Vacuolen habe ich, wie die meisten Autoren, in den Ganglienzellen sehr häufig gesehen. Wie weit dieselben intra vitam wirklich vorhanden sind, ist noch immer nicht genügend geklärt. Während z. B. Nerlich') an einem Falle von Kopftetanus die "nach vorsichtigster Erhärtung" des Organs überaus reichliche

1) Nerlich, eit. nach Leyden und Goldscheider, Die Erkrankungen des Rückenmarks und der Medulla oblongata. Bd.I. S. 75. 
Vacuolisirung der Ganglienzellen des motorischen Trigeminus-, Facialis - und Hypoglossuskernes bereits für vital anspricht, stehen Goldscheider und Leyden') auf dem Standpunkt, "dass die Vacuolen als solche nie im Körper vorhanden sind, sondern sich nach der Härtung entwickeln," und auch ich stehe an, aus ihrem Vorhandensein irgend welche Schlüsse zu ziehen. Gerade bei diesen Gebilden muss man sich stets vor Augen halten, wie unzulänglich unsere gewöhnlichen Härtungs- und Färbemethoden zur Untersuchung der Ganglienzellen sind, und dass, wie in letzter Zeit öfters betont worden ist, sicherlich zahlreiche Leichenveränderungen und Artefacte bei der Conservirung und Anfertigung des Präparates ihr Spiel treiben, die einen grossen Theil der Pathologie der Ganglienzelle in Zweifel stellen. So schreibt z. B. Schulz ${ }^{2}$, dass „die Hypertrophie und hyaline Schwellung der Ganglienzellen nur in ibrem höchsten Grade und bei Vorkommen noch anderer, besonders entzündlicher Veränderungen als pathologisch aufzufassen seien", und ganz ähnlich äussert sich Schultze ${ }^{3}$ ) zu einer Arbeit Kreissig's $\left.{ }^{4}\right)$. -

Sind somit die Veränderungen trügerisch, die wir an der Ganglienzelle finden, so ist andererseits auch ihre, wie es oft scheint, völlige Intactheit durchaus fraglich und zweifelhaft. Es ist schon verschiedentlich beobachtet worden, und ich kann dies bestätigen, dass man manchmal zu seiner grossen Ueberraschung inmitten stark destruirender Prozesse plötzlich eine scheinbar durchaus unveränderte Ganglienzelle antrifft. So sah ich einmal in einem Präparate von multipler metastatischer Carcinomatose des Gehirns einzelne sehr wohl erhaltene Ganglienzellen von Krebsmassen fast ummauert. Diese Intactheit kann wohl nur eine scheinbare sein, und ich habe die Ueberzeugung, dass schon

1) a. a. 0 .

2) Schulz, R., Neurolog. Centralbl. 1882. No. 23, 24.

3) Schultze, Zusătzliche Bemerkungen zu dem Aufsatze des Herrn Dr. Kreissig. Dieses Archiv. Bd. 102.

4) Kreissig, Ueber die Beschaffenheit des Rückenmarks bei Kaninchen und Hunden nach Phosphor- und Arsenikvergiftung nebst Untersuchungen über die normale Struktur desselben. Dieses Archiv. Bd. 102. S. 286 . 
die Nissle'sche Alkohol-Methylenblau-Methode Veränderungen bewiesen haben würde, welche, bei dem complicirten Bau der Ganglienzelle, bereits eine sehr schwere Schädigung bedeuten können.

Die histologischen Veränderungender weissen Substanz bieten zunächst im Allgemeinen nur die bekannten Degenerationszustände der Nervenfasern dar, die in einer primären Schwellung der Axencylinder mit folgender Verdünnung der Markscheiden und Undeutlichwerden der concentrischen Ringelung beginnen, schliesslich zur Weitung und zum vollständigen Schwunde der Markscheide führen und auch den, oft enorm geschwollenen, Axencylinder, der zuerst noch gut, dann immer schlechter färbbar wird, zur Vacuolisirung und zum bröckligen Zerfall bringen, so dass schliesslich nur noch eine leere, erweiterte Neurogliamasche zuräckbleibt. Nach meinen Präparaten stellen sich in dieser Weise die Veränderungen hauptsächlich in den inselförmigen Degenerationsheerden dar. Hier haben offenbar die Schädlichkeiten besonders auf die Ieichtverletzliche Nervensubstanz eingewirkt und zwar so schnell, dass das langsam wachsende Zwischengewebe nicht im Stande war, die maschigen Defecte zu füllen. Etwas anders ist es in den Partien der strangförmigen secundären Degeneration. Dieselben machen schon durch ihre Gleichförmigkeit den Eindruck eines langsam fortschreitenden, alle Gewebselemente gleich betheiligenden Prozesses, der zwar auch mit Axencylinder-Veränderungen beginnt, dann aber auch das interstitielle Gewebe genügend zur Proliferation kommen lässt. So kommt es, dass wir an guteingebetleten Präparaten nur selten eine grössere Anzahl von Maschen in den secundär entarteten Partien finden. Es verhalten sich demnach, wenn ich Analoga aus der Pathologie der drüsigen Organe herbeiziehen darf, die Vorgänge der primären und secundären Entartung etwa wie eine traumatische Leberwunde zur Lebercirrhose.

Die vieldiscutirten Fettkörnchenzellen wurden in etwas grösserer Menge nur im Fall III angetroffen, wo sie in Folge der Osmiumbehandlung sehr schön zu sehen waren. Auf die vielfachen Erklärungsversuche ihrer Entstehung möchte ich nicht näher eingehen, da sich an zablreichen anderen Orten umfassende Zusammenstellungen über diesen Gegenstand finden. Meines Er- 
achtens hat Stroebe's ${ }^{x}$ ) Anschaung, dass, unbeschadet der Genese sonstiger Fettkörnchenzellenarten, die hier vorliegenden Körnchenzellen theils aus polynucleären (selten aus mononucleären) Leukocyten, theils aus Bindegewebszellen (Blutgefässwandzellen) entstehen, die grösste Wahrscheinlichkeit und ist wohl als bewiesen anzusehen.

Ebenso gesichert erscheint mir durch denselben Autor ${ }^{1}$ ) die Genese der sogenannten Amylumkörperchen aus degenerirten Nervenfasern. Ich selbst fand dieselben nur spärlicb, was immerhin im Vergleich zu den Schilderungen anderer Autoren auffallend ist.

Der Centralkanal war hie und da obliterirt, einmal etwas erweitert, Veränderungen, denen beiden keinerlei pathologische Bedeutung innewohnt.

Die eigenartigen, endothelartigen Zellen, die zuerst von Leyden ${ }^{2}$ ), sodann auch von Scbultze ${ }^{3}$ ), Kahler und Pick ${ }^{4}$ ) und Schmaus ${ }^{5}$ ), der sie zum Theil für entfettete Fettkörnchenzellen, also für Artefacte, hält, beschrieben worden sind, kamen nicht zur Beobachtung.

Von ausserordentlicher Bedeutung ist nun noch die Betrachtung der Gefässe. Dieselbe war besonders interessant und dankbar an den mit Saffraninfärbung combinirten Osmiumpräparaten. Bei dieser Methode färbten sich nehmlich die rothen Blutkörperchen intensiv rosenroth (und zeigten sehr schön das Rollet'sche Fadengerüst), während gleichzeitig zwischen ihnen die mit Gewebstrümmern beladenen Fettkörnchenzellen überaus deutlich hervortraten. Andererseits war auch die Nigrosin-Säurefuchsin-Färbung

1) Stroebe, Experimentelle Untersuchungen über die degenerativen und reparatorischen Vorgänge bei der Heilung von Verletzungen des Rückenmarks nebst Bemerkungen zur Histogenese der secundären Degeneration im Rückenmark. Jena 1894.

2) Leyden, Beiträge zur pathologisehen Anatomie der atrophischen Lähmungen des Kindes und des Erwachsenen. Archiv für Psych. Bd. VI. 1. S. 271.

3) Schultze, F., Sitzungsbericht der 2. Wanderversammlung der südwestdeutschen Neurologen und Irrenärzte. 1877. VII. S. 223.

4) Kahler und Pick, Beiträge zur Symptomatologie und pathologischen Anatomie der Rüekenmarkscompression. Archiv für Psych. Bd, X. S. 186.

5) Schmaus, Die Compressionsmyelitis bei Caries der Wirbelsäule. Wiesbaden 1889 . 
wegen der scharfen Absetzung der Gefässadventitia gegen das umliegende Nervengewebe werthvoll und sehr wohl verwendbar.

Es zeigte sich nun, dass wesentliche Gefässveränderungen nur an den Compressionsstellen und deren Umgebung bestehen. An ihrer horizontalen Vertheilung (im Querschnitt) lässt sich eine besondere Gesetzmässigkeit nur insofern aufstellen, als sie an der dem andrängenden Tumor entsprechenden Seite stärker ausgesprochen zu sein pflegen, als auf der anderen. Besonders ist dies für das arterielle Gefüsssystem der Fall.

Was nun zunächst das betroffene Gefäss gebiet anlangt, so sind zweifelohne die abführenden Gefässe (einschliesslich des Lymphsystems) weit mehr als die Arterien betheiligt. Dies äussert sich in einer zum Theil mächtigen Ueberfüllung der Lymphgefässe, der Venen und schliesslich auch der Capillaren. Speciell in den letzteren fanden wir mehrfach eine so enorme Füllung, dass, wohl unter der übermässigen Spannung, zu beiden Seiten des wurstförmig prall gefüllten und gewundenen Gefässrohres kleine Hämorrhagien erfolgt waren. Am meisten afficirt aber sind die Lymphbahnen. Als breite Spalten, die von geronneven, in Fall III reichlich mit Fettkörnchenzellen untermischten Massen erfüllt sind, durchfurchen sie den Querschnitt und theilen ihn förmlich in eine Anzahl Felder ein, die ihm manchmal makroskopisch ein eigenartig schematisches Aussehen verleihen. Bei mikroskopischer Betrachtung mit stärkeren Vergrösserungen erblickt man an gut eingebetteten Präparaten allenthalben feinste Lymphspalten, welche kleine Gruppen von bald mehr, bald weniger degenerirten Nervenfasern umspülen.

Im Gegensatze hierzu finden wir im arteriellen Gefässgebiete nur selten Füllung von normaler Stärke, geschweige denn Hyperämie an; vielmehr herrscht hier eine auffallend geringe Blutmenge entschieden vor. Dass hierbei etwa wesentliche artificielle Veränderungen ihr Spiel getrieben haben könnten, erscheint schon deshalb unwahrscheinlich, weil ja die zugehörigen vepösen Gefässe ihren Inhalt durchaus gut bewahrt hatten.

Fast wichtiger noch als diese positiven Befunde an dem Gefässsystem ist ihre negative Seite, nehmlich vor Allem das gänzliche Fehlen von arterieller Hyperämie, von Gefässneubildung und von Rundzelleninfiltration um die Gefässe oder weiterhin im 
Gewebe. Damit aber vermissen wir diejenigen drei Momente, die wir heutzutage als die Hauptkriterien der Entzündung ansehen, und gerade an meinen, sämmtlich schnell verlaufenden und daher relativ frischen, Fällen scheinen mir diese Beobachtungen nicht ohne Bedeutung zu sein. Liefern sie doch wiederum den Beweis dafür, dass die Entzündungserscheinungen, die von anderen Autorén hierbei beschrieben worden sind, lediglich secundärer Natur sein müssen, ein Standpunkt, den u. A. auch E. Kaufmann ${ }^{1}$ ) in seinem neuen Lehrbuch der speciellen Pathologie vertritt. Nach unserer Auffassung ist demnach die sogenannte Compressionsmyelitis durch Wirbeltumoren ein degenerativer Prozess, der stets durch ödematöse Durchtränkung, oft auch durch arterielle Anämie, bezw. Ischämie und schliesslich auch durch directe Compression des Rückenmarks hervorgerufen wird, falls für die letztere die Duraverdickung und die andrängenden Tumormassen mächtig genug geworden sind. Wie jenes Oedem allerdings zu Stande kommt, ist vor der Hand nicht nach allen Richtungen hin sicher za stellen. Zweifellos stellt die nachweisbare, schwere Behinderung der abführenden Gefässe einen Hauptfactor hiorbei dar. Ferner lässt sich nach Enderlen's ${ }^{2}$ ) Vorgang auch ungezwungen annehmen, dass, sei es von den zu Zerfall neigenden Tumormassen, sei es von bereits zerstörter Nervensubstanz her lähmende Einflüsse auf die Vasomotoren ausgeübt werden, welche zu einer Vermehrung der Gewebsflüssigkeit führen können. Dass sich diese seröse Durchtränkung noch mit einer schlechten arteriellen Versorgung paaren kann, sehen wir ganz besonders in Fall I ausgeprägt, wo das stark wuchernde Carcinom auf seinem Wege durch das Foramen intervertebrale die Arterie dicht umschlossen and fast gänzlich verengt hatte. Endlich ist ja wohl kaum zu bezweifeln, dass so mächtige intraspinale Neubildungen, wie sie uns in Fall I und II entgegentreten, bei längerer Dauer auch directe Druckwirkungen auf das Rückenmark ausüben und das Gewebe für die beiden erstgenannten Schädlichkeiten noch empfindlicher machen werden.

1) E. Kaufmann, Lehrbuch der speciellen pathologisehen Anatomie. Berlin 1896. S. 839.

2) Enderlen, Deutsche Zeitschr. für Chirurgie. Bd.40. 3 und 4. 
Zum Schlusse ist es mir eine angenehme Pflicht, Herrn Geh. Medicinalrath Prof. Dr. Ponfick für die freundliche Anregung zu dieser Arbeit, für die rege Theilnahme an derselben, sowie für die gütige Ueberlassung des Materials, Herrn Geh. Medicinalrath Prof. Dr. Kast und Herrn Prof. Dr. Buchwald, meinem hochverehrten Chef, für die liebenswürdige Ueberweisung der klinischen Notizen, Herrn Prof. Dr. E. Kaufmann für seinen entgegenkommenden Rath bei Anfertigung der Bildertafel meinen ergebensten Dank auszusprechen.

\section{Erklärung der Abbildungen.}

Die Abbildungen sind nach den zugehörigen Präparaten gezeicbnet und im Verhältniss von $1: 2$ vergrössert.

Fall I.

Höhe des

$\mathrm{C}_{1} \quad$ 1. Halswirbels

$\mathrm{C}_{2 \mathrm{a}}$ 2. . - (oberer Theil) $\left.{ }^{1}\right)$

$\mathrm{C}_{2 b}$ 2. - (unterer Theil)

$\mathrm{C}_{3} 3$, -

$\mathrm{C}_{4}$. 4 .

$\mathrm{C}_{\mathrm{G}} 6$.

$D_{1} \quad$ I. Brustwirbels

$\mathrm{D}_{3} 3$. -

$\mathrm{D}_{5} 5$.

$D_{7} \quad 7$.

\section{Fall II.}

Höhe des

$\begin{array}{llll}\mathrm{C}_{7 a} & 7 . \text { Halswirbels (oberer Theil) } \\ \mathrm{C}_{7 b} & 7 . & - & \text { (unterer Theil) } \\ \mathrm{D}_{1 \mathrm{a}} & 1 . & \text { Brustwirbels } & \text { (oberer Theil) } \\ \mathrm{D}_{1 \mathrm{~b}} & 1 . & - & \text { (unterer Theil) } \\ \mathrm{D}_{2 \mathrm{a}} & 2 . & - & \text { (oberer Theil) } \\ \mathrm{D}_{2 \mathrm{~b}} & 2 . & - & \text { (unterer Theil) } \\ \mathrm{D}_{3 \mathrm{a}} & 3 . & - & \text { (oberer Theil) } \\ \mathrm{D}_{3 \mathrm{~b}} & 3 . & - & \text { (mittlerer Theil) } \\ \mathrm{D}_{3 \mathrm{c}} & 3 . & - & \text { (unterer Theil) } \\ \mathrm{D}_{4} & 4 . & - & \end{array}$

Fall III.

$\mathrm{D}_{1}$ Höbe des 1. Brustwirbels

$\begin{array}{llllll}\mathrm{D}_{2 \mathrm{a}} & - & - & 2 . & - & \text { (oberer Theil) } \\ \mathrm{D}_{2 \mathrm{~b}} & - & - & 2 . & - & \text { (unterer Theil) } \\ \mathrm{D}_{3 \mathrm{a}} & - & - & 3 . & - & \text { (oberer Theil) } \\ \mathrm{D}_{3 \mathrm{~b}} & - & - & 3 . & - & \text { (unterer Theil) } \\ \mathrm{D}_{4 \mathrm{a}} & - & - & 4 . & - & \text { (oberer Theil) } \\ \mathrm{D}_{4 \mathrm{~b}} & - & - & 4 . & - & \text { (unterer Theil) } \\ \mathrm{D}_{5} & - & - & 5 . & - & \\ \mathrm{D}_{6} & - & - & 6 . & - & \\ \mathrm{D}_{\gamma} & - & - & 7 . & - & \end{array}$

1) Die in Fall I und II mitgezeichneten unregelmässigen Gebilde stellen die Querschnitte der Tumormassen vor. 